\title{
Learning to Swim in the Pool Before Surfing in the Sea: A Study of Local Innovation Experimentation
}

\begin{abstract}
Successful development of complex innovations require firms and key partners to perform a series of experimentation activities at local small-scale society at first, which we define such strategic process as Local Innovation Experimentation (LIE). Doing so helps managers grasp a complete map of technical and non-technical dimensions about the proposed innovation, around which build viable innovation ecosystems to gain advantages. To know what could affect the extent to which managers have high level of LIE performance, we adopt the managerial dynamic capabilities framework. Using a sample of 111 Chinese innovative firms, we find significant relationships among managers’ capability portfolio, local innovation support, and LIE. PLS-SEM results indicate that managers with greater metacognitive capability, networking capability, learning agility have better LIE performance. Besides, (1) frequent attending local networking events and networking capability, (2) frequent use of innovation facilities and learning agility, interact in their positive effects on, and therefore result in, better LIE performance. Based on these findings, our core theoretical contribution lies in that a capability portfolio perspective at the lower (firm) level contributes to a better understanding of innovation ecosystem birth at higher (ecosystem) level.
\end{abstract}

\section{Keywords:}

local innovation experimentation; metacognitive capability; networking capability; learning agility; local innovation support 


\section{Learning to Swim in the Pool Before Surfing in the Sea: A Study of Local Innovation \\ Experimentation \\ INTRODUCTION}

Designing and performing local innovation experimentation is fundamental for firms developing new complex innovations. Local Innovation Experimentation (hereafter we use LIE) refers to a strategic innovation process that a focal firm together with its key partners test the feasibility of new innovative products (services/processes) in a local small-scale society in order to make them mature enough to enter the mass societies. Compared to regular market testing practices (Dolan \& Matthews, 1993; Gruner \& Homburg, 2000; Klompmaker, 1976; Piller \& Susumu, 2006), LIE involves a wider range of ecosystem actors, such as socio-political actors like governments and citizen groups, next to the usual economic collaborators such as customers, retailers, and suppliers.

Consider a typical example in bike-sharing industry, Han et al. (2018) found that two bikeChinese sharing ventures (Redbike and Yellowbike) experimented with innovative smart dockless sharing bikes in small-scale societies (i.e., Yangpu District of Shanghai and Beijing college campus). By a set of experiments with different actors such as riders and local governments, they were able to explore multi-facet dimensions of the feasibility for sharing bikes, such as technical features, realworld riders feedbacks, competitors’ reactions, and social and regulatory attitudes. As a result, two ventures were able to develop bike-sharing ecosystems around new complex innovations (Dougherty \& Dunne, 2011; Liu \& Rong, 2015; Lütjen et al., 2019). In contrast, their two strong competitors did differently. Bluebike skipped localized experimentation process and rushed into the mass societies directly; Greenbike operated the experimentation process ineffectively because they misinterpreted feedbacks from the local traffic management bureau. No or ineffective LIE resulted two competitors into a failure of their bike-sharing ecosystems. 
The aforementioned example shows that LIE is crucial for innovative firms' survival and developing innovation ecosystems by aligning wider ecosystem actors. However, achieving high LIE performance is challenging. First, keeping "minimum but viable" partners in LIE activities is problematic. LIE is time-consuming which needs key partners' considerable investment into value co-creation (Chesbrough \& Teece, 1996). Yet whether experimented innovations could be turned into commercially valuable ones is unknown to all involved experimenters (Pekkarinen et al., 2020). Due to different perceptions of uncertainties about whether the investment will pay off, aligning partners' expectations and commitment become difficult for managers of focal firms.

Second, specific capabilities are required to interpret diverse feedbacks from actors in smallscale societies whose complex interactions would hamper LIE performance. Prior literature has articulated that market testing practices aim to cope with new products' technical uncertainties and competitors reactions, with a focus on the economic environment (Cooper \& Kleinschmidt, 1994; Di Benedetto, 1999; Klompmaker, 1976; Piller \& Susumu, 2006). Beyond the economic environment, LIE requires managers to work additionally around non-technical uncertainties (regulatory compliance and societal fitness) in the socio-political environment where managers could exercise limited impacts. It is plausible that during new products' ongoing exposure to publics, on-site feedbacks from both the economic and the socio-political environments are not straightforward as in regular marketing tests, but often interacted, surprising, and seemingly random (Gillier \& Lenfle, 2019). Such feedback ambiguity causes problems for managers to make precise interpretations and strategies about proposed innovations.

Third, associated with the feedback ambiguity, new technical and non-technical problems encountered during LIE process are just unpredictable, posing challenges for experimenters to make trade-offs between different dimensions of new products. Unlike regular market tests that search mainly for best answers of technical dimensions on proposed innovations, managers in LIE seek 
additionally to pinpoint the scope of non-technical dimensions (e.g., governmental restriction and social refusal). Often they have to sacrifice technical dimensions to meet changeable demands from for example local regulatory agencies (Han et al., 2018; Oskam et al., 2020). To what extent managers could balance best the technical and non-technical dimensions therefore determines whether or not new innovations would be successful in mass societies (see Pekkarinen et al., 2020).

Because of typical challenges, that is, partner instability, feedback ambiguity, and problem complexity inherent in LIE process, it becomes important to understand how managers can address them effectively to achieve high LIE performance. However, to date, scholars showed merely key principles of LIE and its connections to new ecosystem birth (Mahmoud-Jouini \& Charue-Duboc, 2017; von Pechmann et al., 2015). When considering new innovation ecosystem birth, literature has indicated that specific dynamic capabilities of focal firms are important antecedents determining whether new innovation ecosystems could take form or not (e.g., Cao et al., 2020; Kashan \& Mohannak, 2017; Velu, 2015). Thus, it is reasonable to anticipate that focal firms' dynamic capabilities is likely to play a vital role in LIE process since it is tied with multiple challenges (Lütjen et al., 2019; Walrave et al., 2018). Hence, our research question is: what organizational capabilities can lead focal firms to have high performance of LIE process?

To answer our research question, we adopted the dynamic managerial capability framework promoted by Adner \& Helfat (2003). We hypothesize that focal firms' capability portfolio, that is, metacognitive capability (top managers' cognition), networking capability (top managers' social capital), and learning agility (top managers' human capital), are associated with high performance of LIE process. Moreover, LIE is a kind of socio-spatially embedded strategic innovation process (Ansell \& Bartenberger, 2016). We hence consider the localized innovation supports, which reflect experimenters' use of various supports offered by geographically adjacent third-parties (Cohen, 2006; Spigel, 2017), as the unique contextualized influence. Because local innovation supports 
influence, acted as vital complements to, firms' capability portfolio, we propose that local innovation supports may affect LIE process via the firms’ three enhanced capabilities.

We run PLS-SEM models to corroborate our hypotheses, by use of a sample of 111 innovative firms that operate in Chinese high-technology industries. Specifically, managers' high levels of metacognition, networking capability, learning agility relate respectively to their (1) effective feedback processing, (2) effective partner management, and (3) effective problem addressing, such that they acquire better LIE performance. Except for the metacognition-LIE relationship, such positive effects would be strengthened when managers are inclined to leverage networking opportunities and diverse innovation facilities offered by local innovation third-parties.

Our study makes two primary contributions. First, by investigating how three capabilities lead to high LIE performance, we contribute to the current innovation ecosystem literature by showing that a capability portfolio perspective at the lower (firm) level contributes to a better understanding of ecosystem birth at higher (ecosystem) level. Second, we contribute at the nexus of capabilities, innovation resources, and innovation practices. Our findings showed that the use of localized innovation supports results into divergence regarding to capability development. This answers recent calls to shift focus to the "bottom-up" paradigm of entrepreneurial ecosystem studies so as to understand how individuals use of local innovation resources lead to organizational or interorganizational results (Spigel, 2018).

\section{THEORY AND HYPOTHESIS DEVELOPMENT}

In this section, we first develop a model of LIE process from the innovation ecosystem perspective. We argue that extant literature underexplored what enables high LIE performance. Then, based on capabilities literature, we posit how three capabilities influence LIE performance, respectively. Taking the innovation context into account, we further hypothesize how the relationships between three capabilities and LIE are contingent on three types of local innovation supports. 


\section{A model of LIE process: An innovation ecosystem perspective}

The LIE may be viewed as a strategic innovation process that involves design, implementation, execution, and refinement of experimentation actions, decisions, and activities for innovation development. LIE is purposely undertook by innovative firms, in an effort to more closely link their new product development activities to the fast-changing demands of competitive environments (Hampel et al., 2020). To illustrate, a big company together with partners work to experiment with new hydrogen-electric solutions (Mahmoud-Jouini \& Charue-Duboc, 2017), or Brazilian ventures conducted collective experiments to test biotech products before they diffuse into mass societies (de Vasconcelos Gomes et al., 2018). As to LIE, first, proposed new innovations are systemic, suggesting that they "can be realized only in conjunction with related, complementary innovations" (Chesbrough \& Teece, 1996: 128); besides, they are complex innovations that “comprise many parts with unknown and unpredictable interactions” (Dougherty \& Dunne, 2011: 1214). Such uncertainties entail experimenters to search generatively for its optimal performance landscape (Dattée et al., 2018; Ganco et al., 2020). Thus, it suggests that focal firms and partners might struggle into liabilities of an innovation ecosystem's nascence where overall perimeters of novel offerings are not stabilized, additional contributors to offerings are not all identified, and interdependency rules between contributors are still not entirely defined (Adner, 2012).

Second, due to proposed innovations' systemic and complex nature, managers should design and perform experimentation activities in an innovation ecosystem scale to reduce uncertainties. That is, in addition to innovations' uncertainties in economic environment (i.e., technical functions, customers’ demands, and competitors’ reactions) that regular marketing Beta tests target (e.g., Di Benedetto, 1999; Klompmaker, 1976), managers aim additionally to find out political/social uncertainties in the socio-political environment (regulators' attitudes and societal feedbacks) (Oskam et al., 2020; Pekkarinen et al., 2020; von Pechmann et al., 2015). 
Third, uncertainties distributed in an ecosystem scale require experimentation activities to be executed in local small-scale societies, such as college campuses (Han et al., 2018), hospitals (Hyysalo \& Hakkarainen, 2014), or specific urban districts (Noel \& Sovacool, 2016). The underlining principle is that unlike in-house experimentations restricted to economic (technical) uncertainties (Ansell \& Bartenberger, 2016; Thomke, 2003), experimenters could collect both economic and socio-political uncertainties within real-world local societies (Mahmoud-Jouini \& Charue-Duboc, 2017; Pekkarinen et al., 2020). Taking such local societies as the springboards, managers through experimentation activities have possibilities to know how different local social and political stakeholders treat the novel products or services. Furthermore, they become more confident to progress towards mass societies with well-aligned economic and socio-political environments which the novel innovations operated into (Han et al., 2018; Walrave et al., 2018).

Despite literature has revealed main principles related to LIE process, the knowledge on what lead to the high LIE performance remain under-investigated. Current researchers have pointed out that ecosystem growth and governance depends largely on focal firms' single specific capabilities (see Cao et al., 2020; Kashan \& Mohannak, 2017; Nambisan \& Baron, 2013; Velu, 2015). But particular individuals as agents of focal firms make sense of and react to multidimensional uncertainties from two ecosystem environments requires a broader thinking of dynamic capabilities (Lütjen et al., 2019; Walrave et al., 2018). Simply, understanding LIE process from the dynamic capability portfolio point-of-view seems to be appropriate. Following this line of thought, we rely on the dynamic managerial capabilities framework promoted by Adner \& Helfat (2003). According to them, "dynamic managerial capabilities reflect three underlying factors: managerial human capital, managerial social capital, and managerial cognition” (Adner \& Helfat, 2003: 1020). We will therefore theorize how focal firms' capability portfolio, including metacognitive capability (top 
managers’ cognition), networking capability (top managers’ social capital), learning agility (top managers’ human capital), influences directly the performance of LIE process.

Besides, existing innovation management research has vastly revealed that results of most strategic innovation projects root in the innovation context they attached to (Autio et al., 2014; Walter et al., 2006; Zahra et al., 2014). LIE is a sort of socio-spatially embedded innovation process (Ansell \& Bartenberger, 2016). So a holistic study of LIE requires the inclusion of salient effects that result from the firms’ capabilities and regional innovation systems experimenters embedded into. Our model hence incorporates three key local innovation supports (i.e., consultancy, network, and facility) as moderating factors (Cohen, 2006; Spigel, 2017). The overall conceptual model

integrating LIE, capabilities, and innovation supports is depicted in Figure 1. In what follows we will demonstrate proposed relationships in the model in greater detail.

\section{Insert Figure 1 here}

\section{Hypotheses development}

Before our six hypotheses development, to be clear is that we see focal firms' three capabilities at the top management team (TMT) level, in that an organization behavior and its performance are a reflection of, and are determined by, its TMT's behaviors and performance (Hambrick \& Mason, 1984). This link is evident when organizations behave strategically to change, adapt, and renew itself for growth and survival under complex, turbulent environments (Carpenter et al., 2004; Teece, 2007). Grounded into these theories, we will explicate how TMTs' metacognitive capability, networking capability, learning agility, which reflects focal firms’ capabilities in cognition (Helfat \& Peteraf, 2015), social capital (Acquaah, 2007), and human capital (Colombo \& Grilli, 2005) respectively, relate closely to the LIE.

Relating metacognitive capability to LIE 
To understand how focal firms conduct LIE effectively, we first focus on the role of metacognitive capability. Following Najmaei and Sadeghinejad (2019), we define metacognitive capability as TMT's ability to reflect upon, understand, and consciously control their own cognitive thinking related to a complex task. Metacognition literature has long demonstrated that under environments featured by high uncertainties, individuals with metacognitive competence would not rely cognitively on single thinking modes, habits, and strategies and thus could better reduce the normal cognitive biases (e.g., overconfidence, self-justification) (Haynie et al., 2012; Zahra \& Nambisan, 2012). Specifically, through high-order cognitive process - "thinking about thinking” (Schraw \& Dennison, 1994), metacognitively aware managers are able to think beyond existing knowledge structures and domain-specific experiences, resulting in multiple decision frameworks that maximize the likelihood of achieving tricky innovation goals (Haynie et al., 2010).

The idea of metacognitive capability is useful in our investigation of effective LIE for three major reasons. First, metacognitively skilled TMTs could better harness various feedbacks emerged from LIE (Mitchell et al., 2011). As demonstrated before, managers decide to implement LIE in order to recognize technical and non-technical feedbacks as complete as possible. But the ambiguity of multiple feedbacks requires to process information systemically. Based on these, studies revealed that metacognitive individuals would like to treat complex tasks in a self-regulated process (Cho \& Linderman, 2019). In this sense, they first analyze where their cognitive strengths and weaknesses lay when feedbacks come in floods. These self-mindful practices help avoid sticking into cognitive biases by detaching themselves from the previous self-centered to a system-level perspective of feedbacks (Kudesia, 2019). Besides, instead of processing feedbacks separately to have one-on-one interpretations, managers detect useful information from the noise by combining different cognitive ways of hypothesizing, thereby providing alternative but reinforced decision approaches to 
feedbacks (Haynie et al., 2010). Last, temporally monitoring implemented strategies lead their metacognitions to adapt to fast-changing environments (Haynie et al., 2012).

Second, metacognitively competent managers are able to tackle with value tensions in LIE process. Value complementors are important for effective LIE, during which experimenters have to place more emphasis on value creation than value co-capture activities (Pekkarinen et al., 2020). Accordingly, tensions arise as the imbalance of value co-creation and co-capture in this process. The co-created value on the ecosystem (not individual) level indicates that early value contributors have the probability of losing benefits from new innovations if the LIE fails (Oskam et al., 2020). To mitigate these drawbacks, managers with high metacognitive skills are deemed to manage excellently discrepant goals than others (Nambisan \& Baron, 2013). They are more capable of employing no-conventional cognitive mechanisms like abductive reasoning or counterfactuals to align the present and future, and to balance the individual and whole (Haynie et al., 2010). In the analysis by Pidun et al. (2020), Airbnb’s early quick success at the U.S. local community was attributed to the metacognitive choices that managers take to balance the tension between value cocapture and co-creation with complementors in the present and future.

Third, metacognitively self-aware managers are said to have high contextual adaptability. Generally, managers select local small-scale societies to do LIE. However, very often is that deliberately selected local societies are different in aspects like end-users, regulation requirements, and cultural preferences, requiring strengthened mental abilities to ensure contextual adaptability (Haynie et al., 2012). Cognitive psychologists argued that managers' high metacognition associates positively with cross-cultural performance, such as creativity, reasoned decision-making, and strong adaptability (Mor et al., 2013). This suggests that cultural intelligent managers rely less on established cultural assumptions; rather, they are more capable of integrating inter-cultural communications, observations, reflections into novel cognitive understandings not accessible for 
individuals with less metacognition (Lorenz et al., 2018). For example, Better Place operated novel full electric vehicles (FEV) at two city regions: Copenhagen and Tel Aviv. They failed due to the failure to interpret Danish end-users' green attitudes toward FEV and Israel governments' regulative focus (Noel \& Sovacool, 2016). Based on the preceding arguments, we hypothesize that:

Hypothesis 1 TMTs with high metacognitive capabilities are more likely to have high performance of LIE process.

\section{Relating networking capability to LIE}

As mentioned, LIE process requires various value complementors which are "minimum but viable". "Minimum but viable" complementors suggest that the unique value could still be created with the smallest, indispensable configuration of complementors (cf. Adner, 2012). To partner with key value contributors, literature has suggested the role of networking capability (Mitrega et al., 2012, 2017), referring to "a firm's ability to develop and utilize interorganizational relationships to gain access to various resources held by other actors” (Walter et al., 2006: 542). In short, direct value actors are viable because their close engagement makes a new innovation's functions realized, improved, or revolutionized under dynamic demands, thus guaranteeing its core value (see Mahmoud-Jouini \& Charue-Duboc, 2017). By tapping into portfolios of social ties, managers can first approach and persuade interested partners by presenting profitable business models (Hallen \& Eisenhardt, 2012), quality intellectual patents (Pidun et al., 2020), huge economic and social value (Doblinger et al., 2019), measurable results from early lead end-users (Dolan \& Matthews, 1993). With persuading efforts, focal firms target to involve key complementors into the shared visions.

After initiating partnerships successfully, focal firms with higher networking capabilities can orchestrate complementors to do sets of future-oriented experiments. Note that key complementors usually come from distant industrial domains, geographically distant areas, and institutional sections

(Furr \& Shipilov, 2018). As refereed, some "uncommon partners", like well-known vehicle 
incumbents and local regulators, presented in Better Place's experimentation activities (Noel \& Sovacool, 2016). Note also that all experimenters are their first time to develop new-to-market complex innovations together, a heightened fear of opportunism and insufficient trust might prosper. The orchestration mechanism, such as building common communication platforms, could enhance mutual trust and cause a sense of membership (Dougherty \& Dunne, 2011); besides, focal firms as the relationship broker purposefully encourage communications among complementors, which in turn favor LIE process (Paquin et al., 2013). Last, through orchestrating complementors, focal firms make them stay in a shared fate so that some big incumbents, if involved, cannot play the dominance (Gassmann et al., 2010). This is often the case for cross-border collaborations where asymmetric power between focal firms and established ones might erode LIE performance.

As a series of experiments need attention, time and resources, superior networking capability suggests that focal firms could sever undesirable partnerships to enhance the efficiency of LIE process (Mitrega et al., 2017). A plethora of innovation literature showed that too much collaborators and too few collaborators have less optimal collaboration performance (e.g., Hottenrott et al., 2016; Lavie, 2007). Expanding on this line of reasoning, we hypothesize that focal firms would proactively sustain the minimum portfolio of experimenters. To do so, they define, stipulate explicit assumptions on new innovations, by which partners who do not perceive acceptable might quit ongoing LIE activities (Prince et al., 2014). In addition, such strategically partner termination decisions lower opportunisms and appropriation risks (Gardetm \& Mothe, 2011; Vaaland et al., 2004). Based on these arguments, we suggest the following:

Hypothesis 2 TMTs with high networking capability are more likely to have high performance of LIE process.

Relating learning agility to LIE 
The key purpose of LIE is to reduce uncertainties on complex innovations (Mahmoud-Jouini \& Charue-Duboc, 2017). It is expected that experimenters might encounter various emergent problems. As such, just as managers expert at problems-solving agility will be rewarded with satisfying innovation results (Atuahene-Gima \& Wei, 2011), so too is better LIE process (von Pechmann et al., 2015). In our study, learning agility refers to managers' operational learning ability to detect problems and improvements, assemble needed resources to launch an appropriate response, judge the benefits and risks of initiating an action, and execute actions with competitive speed and flexibility (DeRue et al., 2012; Sambamurthy et al., 2003). Emphasizing the swiftness and flexibility of problems addressing in LIE process is advantageous, for two important reasons.

First, high level of learning agility confers focal firms first mover advantages since they balance well the cost, quality, and profitability about proposed innovations. During experiments, agile managers would be more sensitive to small improvements, mismatches, abnormalities related to the innovation's real-time performance. For improvements, they leverage fast time learning circles to iterate quickly fresh knowledge into next rounds of experiments, thereby reducing innovation exposure risks with the most up-to-date components in innovations (Schuhmacher et al., 2018; Stanko et al., 2014). When detected subtle mismatches and abnormalities, agile learners are capable of taking initiative to propose creative solutions by exchanging new information, knowledge, and resources with key complementors frequently (Overby et al., 2006). So, such collective efforts sparked by active leaners make them subject not to the cost and time pressures.

Second, managers with the learning agility defend their leadership during LIE process. As described in the foregoing paragraph, problem detecting and solving requires complementors' efforts, which allows parties to co-develop a nuanced understanding of what goes on in each other's activities and thus respond quickly and adapt to emerging demands or sudden changes encountered (Seidl \& Werle, 2018). From this perspective, learning agility is a shared capability and the 
asymmetric capability distribution exists among focal firms and complementors (Carmeli et al., 2017). However, the higher leaning agility that focal firms possess than complementors, the more likely they can safeguard leadership during LIE process. This is rewarding when big established firms, who are featured with high learning abilities, stay in the network of experimentation activities (Diestre \& Rajagopalan, 2012). The outperformed skills in pinpointing changes, and further, proposing alternative high-quality solutions ensure that focal firms lead the navigation of LIE process, rather than being bypassed or replaced by peer learners. We hence have the following:

Hypothesis 3 TMTs with high learning agility are more likely to be successful in LIE process.

\section{Relating local innovation support to LIE}

Given that LIE is a socio-spatially embedded innovation process (Autio et al., 2014; Grashof et al., 2019; Zahra \& Wright, 2014), we then seek to understand the effect of local innovation support on the relationship between three capabilities and LIE. Our theorizing builds on especially on entrepreneurship ecosystem research that emphasizes a network of structural, systemic supports to innovation opportunity pursuit, experimentation, scale-up intrinsic to LIE process (Autio et al., 2018; Mason \& Brown, 2014). By local innovation support, we mean the local supporters' act of providing experimenters with access to valued resources to fulfill innovation goals (Kaufmann \& Tödtling, 2002; Patton \& Kenney, 2005); supports are “material-relevant” (Spigel, 2017), being either convenience-based where supporters expect economic compensations, or value-based where there is no expectation of reciprocity (Hanlon \& Saunders, 2007). In all, our expectation is that managers obtain greater LIE results if they approach various innovation supports (e.g., consultancy, network, and facility) offered by local agencies.

The first expectation is that approaching consultancy services help focal firms perform LIE better. First, domain-specific insights into acquired feedbacks enable the sharpness of metacognitive analyzing process. On the one hand, though managers are metacognitive aware, very often is that 
they short of domain-specific knowledges and experiences are new to experiment with new products under uncertain environment. On the other hand, local agencies’ in-depth insights as "raw materials” of cognitive values are accessible to managers, resulting in well-founded strategic decisions. Second, consultancies from credible sources, like investment agencies, capitalist, experts, help managers cross-check profoundly whether metacognitive interpretations of feedbacks are tenable or not, thereby assisting forming consistent experimentation strategies (Mitchell et al., 2011). Such benefits are more evident when focal firms decide to experiment with new innovations in foreign, unfamiliar regions (Noel \& Sovacool, 2016). In this scenario, managers who are more inclined to make use of local consultancy services, such as marketing entry advices, investment suggestions, regulative comments, might have better LIE results than others not. Hence,

Hypothesis 4a More frequent using professional (e.g., marketing, financial, and regulative) consultancy services offered by local agencies strengthens the positive effect of focal firms' metacognitive capability on performance of LIE process.

Our second expectation comes down to that various networking activities offered by local thirdparties promote higher LIE performance. First, managers are more able to win targeted complementors' interests that are industrially or geographically remote by fully capitalizing on networking opportunities, such as business conferences and technology communications. Consider that ambitious managers desire to experiment with new innovations in regions with high degree of foreignness. They acquire legitimacy effectively from attending networking activities organized by local agencies (e.g., chamber of commerce or international consortia) whose endorsements pave the way for first-time collaborations (Parente et al., 2019). Second, through networking events, such as academic conferences, technology transfers, trade exhibitions, focal firms have opportunities to prefect new innovations by absorbing advanced technologies. As a result, key partners' long stay in LIE activities could be confirmed along with the enhanced success rate of new innovations. Third, 
activities like industrial standard-making meetings contribute to the stability of participants in LIE process. According to Giudici et al. (2018), neutral third-parties independent of economic interests are in their best position to solve collaborative conflicts. Therefore, mutual understanding and trust between experimenters will be improved by such local arbitrators' networking events. Thus,

Hypothesis $\mathbf{4 b}$ More frequent using networking activities arranged by local innovation agencies strengthens the positive effect of focal firms' networking capability on performance of LIE process.

Our third expectation is that managers making most use of enabling facilities have better LIE results. A fundamental assumption is that managers would be overwhelmed by flooding feedbacks that are messy and emergent, when their experimentation activities (1) are in early periods, or (2) expand into parallel regions simultaneously (Mahmoud-Jouini \& Charue-Duboc, 2017). As such, localized innovation-related infrastructures, such as test centers, IT digital equipment, and specialized manufacturing facilities, offer an excellent vehicle to offset liabilities of managers' limited attention and feedback processing capacity. To this purpose, first, various innovation facilities, such as real-time data monitoring systems/platforms, not only help data collection, but function to translate, combine, filter, align on-site data so that reliable insights and foresights into new innovations can be much consolidated (Overby et al., 2006; Sambamurthy et al., 2003). Second, well-architected innovation facilities reinforce experimenters’ response capability. For example, some emergent technical needs could be only materialized by sophisticated devices owned by local universities or national labs (Mason \& Brown, 2014; Spigel, 2017). In addition, the presence of integrated facilities, like public living labs, offer managers realize complex technical requirements all together (Hyysalo \& Hakkarainen, 2014). In sum, we conclude: 
Hypothesis 4c More frequent using innovation facilities provided by local innovation agencies strengthens the positive effect of focal firms' learning agility on performance of LIE process.

\section{DATA AND METHODOLOGY}

\section{Research setting and data collection}

Since no public dataset offers all of the information needed to test our hypothesized relationships, we use the questionnaire survey method to collect our data. Prior to conduct the survey, a questionnaire (in English) was designed and the scales were checked iteratively, to enhance the content validity. Indicators for LIE (dependent variable), three capabilities (independent variable), and local innovation support (moderator) were adapted from (or inspired by) the current literature.

Our data collection process involved two major steps. First, we conducted interviews with six science park managers in Netherlands (four) and China (two), as well as a trial surveying with 16 respondents from these science parks. Feedbacks from them have three benefits. We were able to pilot-test our moderating effects. For example, we asked managers such as "In terms of the above examples you give, any companies seek help from your science park management team to carry out local innovation experimentation? If yes, what are the specific supports/services you provide to them?”. Second, we were better able to pinpoint where the respondents distribute. As one respondent suggested, "possibly, SME collaboration platforms might have enough examples. According to my experience, there are some doing innovation experiments...”. Third, we can better deal with issues such as wording, grammar, readability, or structure/layout of our survey.

Second, we selected two Chinese innovation-oriented platforms, i.e., Newba and Koochang, to get access to a representative population consisted of 111 valid responses. These two platforms are suitable because they consist of enough samples that tend to develop new products or services by allying cross-industry partners. As the Newba CEO said, "our platform is the one that promotes 
‘cross-border' innovation”. It is therefore argued that because of the newness of products or services to the market, firms might need the LIE to increase the success rate. To provide a greater clarity of items, the survey was translated into Chinese. The first author and a hired translator used the back translation method to ensure that the identical or an adequate similar meaning remains across the two language versions (Brislin, 1970). Next, (1) to ensure that surveys were completed by respondents, we used Wenjuanxin (a web-based survey instrument like Qualtrics) to collect the data between 19 March to 19 June 2020. (2) We initially received 124 responses from top managers. They were allowed to fill in the survey after they had been informed of thinking of one of latest innovation projects which resembles the LIE as we defined. To ensure respondent competency, managers were only those who were part of the decision-makers concerning the referred innovation project(s). (3) Six responses of 124 with more than 90\% repeated values (e.g., answering strongly (dis)agree with almost all items) were removed from the data set, in order to mitigate the negative impact of data skewness on parameter estimation and confidence intervals. (4) Further, the other seven responses of remaining 118 using less than 300 seconds were deleted after checking the timestamps of each response — this ensured that surveys were carefully treated by informants.

Table 1 provides descriptive statistics of final sample $(\mathrm{N}=111)$. As shown, 60 respondents (54.1\%) are from four innovation hubs in China (i.e., Beijing, Shanghai, Guangzhou, and Shenzhen), where contrasting to others, well-architected innovation resources are accessible for firms (see the recent report by CBRE, 2019). Over a half of the sample are younger than ten years (51.3\%). The simultaneous examination of both new firms and established firms provide much reliable results. Besides, our $44.1 \%$ of sample are firms with full-time employee over 500, indicating a balanced distribution of both SMEs and big firms. Finally, a typical feature of our sample is that most of them belong to emerging high-tech industries (next-generation mobile communication technology, 15.3\%) 
or cross-border industrial domains (renewable energy and new material, 28.8\%; electric vehicle and mobile Internet, 24.3\%; manufacturing and AI, 14.4\%; biomedicine and devices, 6.3\%).

\section{Insert Table 1 here}

\section{Measurement}

Measurement specification requires operationalizing measurement models as either reflective or formative (Bollen \& Lennox 1991). This choice in turn guides the selection of appropriate methods for subsequent data reliability and validity assessments (Diamantopoulos \& Winklhofer 2001).

Specifically, for three capabilities and three types of local innovation support, we adopted previously validated measures for the survey; inspired by prior experimentation literature, we created threeitem instrument to measure LIE.

Dependent variable. LIE was measured as a first-order formative construct comprising three items. Given LIE scale is unavailable in previous literature, we developed relevant scales by following theoretical guidelines (Diamantopoulos \& Winklhofer 2001). First, we propose initial dimensions and indicators by referring particularly to Thomke (1998, 2003), whose characterizations of experimentation in developing new products has seven key aspects: fidelity, refinement, cost, duration, timing in progress, knowledge target, and participants involved. Relevant items were initially co-developed by authors according to these seven aspects. We then circulate LIE definition, seven dimensions, and initially proposed indicators with three innovation professors and three industry experts, through which two rounds of reviewing processes ensured that three of seven key aspects - involved participants, fidelity, knowledge target - are fundamental to LIE. Second, we operationalized the three aspects into relevant indicators which were reviewed by two academic entrepreneurs, four experts, and ten doctoral researchers.

To measure LIE performance, respondents needed to report their recent innovation project(s) during which they executed LIE by (1) collaborating with different ecosystem partners (ranging 
from "the same industry", "totally different industry”, "university/research institutes", “governmental partners” to "societal partners”), (2) experimenting products with real-life users in different developmental stages (ranging from “innovation ideas”, “mock-ups”, “initial prototypes”, “improved versions” to “ready-for-mass-market”), and (3) receiving on-site feedback on proposed products (ranging from “technical functions”, "real-life end-users’ demands”, “competitors' reactions”, “political agencies’ attitudes” to “societal stakeholders’ attitudes”). We measured each indicator (Experiment_1 to Experiment_3) as the sum of the items, ranging from " 0 " to “5”.

Independent variable. Three capabilities were reflective variables and used seven-point Likert scales $(1=$ strongly disagree; 7 = strongly agree). Specifically, metacognitive capability was measured using 19 items adopted from Haynie and Shepherd (2009), which comprises two subdimensions: metacognitive knowledge (items Metacog_11 to Metacog_111) and metacognitive experience (items Metacog_21 to Metacog_28). These items capture TMT members' treatments of important management and operation activities/decisions in turbulent environments. We asked for example: "Our TMT members can think of several solutions to solve a problem and choose the best one.”. The measurement of networking capability followed Mitrega et al. (2012). These items measured managerial practices in terms of how CEOs manage strategic collaborations (items Network_1 to Network_7). Likewise, a representative questions is: “We try many ways to persuade and "lock in" our partners in cooperation with us.". Learning agility was to assess the speed of problem sensing (items Learn_11 to Learn_14) and solution quality (items Learn_21 to Learn_23) when top managers solve problems during innovation development process. Seven items from Atuahene-Gima and Wei (2011) was adopted. A typical question is “our company was always able to quickly recognize small mismatches/abnormalities during our product development process”.

Moderators. We measured local innovation support with three first-order reflective constructs ( 1 = very rarely used; 5 = very often used). We followed Spigel (2017) who suggested that three 
“material-relevant” types of supports (i.e., consultancy services [Support_11 to Support_14], networking activities [Support_21 to Support_24], innovation facilities [Support_31 to Support_34]) offered by local institutions are vital for firms' innovation activities. For example, we asked respondents: how often do you use the following local consultancy services to facilitate new product development activities: (a) market consultancy services; (b) regulation consultancy services; (c) financial consultancy services; (d) other related consultancy services, such as (...).

Control variable. We included ten controls in our analysis, as these variables have been found to directly or indirectly influence LIE performance. First, we controlled for "innovation hub" as the closer the innovative firms get to four innovation hubs (Yes = Beijing, Shanghai, Guangzhou, and Shenzhen; No = others), the more likely they will notice and leverage innovation supports from local institutions (Spigel, 2017), thereby possibly increasing the performance of LIE. Second, we considered "firm age” (year), "firm size” (the number of full-time employees), and "firm structure" (number of management layers and departments). Our choice of these is grounded on their acknowledged influence on learning agility (Atuahene-Gima \& Wei, 2011) and our dependent variable LIE (Thomke, 2003). Third, “TMT number”, “TMT industry diversity”, “TMT education diversity” needed to be controlled as capability literature has already suggested that they correlate positively with the level of managers' metacognitive capability (see Mitchell et al., 2011) networking capability (see Mitręga et al., 2017), and learning agility (Sambamurthy etal., 2003), which in turn might influence LIE performance. Finally, “TMT risk propensity” and "innovativeness of products” associated closely with CEOs' decisions to carry out LIE (Thomke, 2003). Four items in Kraiczy et al. (2015) were employed to assess TMT's overall propensity to risk, either being risk preference or risk aversion. Six items from Talke et al. (2015) were averaged to assess whether innovative products adopt new technologies and are new to markets or not. 
Common Method Bias (CMB). We took several steps to alleviate concerns on CMB of our collected data. When designing the survey, the study used different response formats and scale endpoints for variables. When surveying, we assured respondents of confidentiality and encouraged honest responses by reminding that there were no right or wrong answers. We also applied Harman's single-factor test by entering all variables into one-factor analysis. The results indicated that no serious single method factor exists (Kock 2015). The first factor accounts for only $17.22 \%$ of the variance, whereas the remaining factors accounts for $63.97 \%$. Furthermore, we used a latent common method factor to estimate the loadings on every item in the PLS path model, in addition to each item's loading on its theoretical construct (Kock 2015). Comparing the estimated path model relationships with and without each additional marker variable, we found no notable differences; all conceptualized paths maintained their statistical significance.

\section{ANALYSIS AND RESULTS}

Prior to our analysis, an assessment of whether our collected data show desirable statistical power is done. In order to estimate the minimum sample size, the ten-times rule, which should consider the variable that has the highest number of predictors, has been used (Goodhue et al., 2012). In our case, six is the maximum number of links pointing at the LIE construct, which means that 60 is the minimum sample size $(6 \times 10=60)$. Further, a G Power Analysis (GPower 3.1.9.4 software) has been performed (Cunningham \& McCrum-Gardner, 2007). Results show that while for a medium effect size $\left(f^{2}=0.30\right)$ at alpha level of 0.05 , we need a minimum sample size of 82 to achieve the acceptable power of 0.800 . Therefore, our sample $\mathrm{N}=111$ exceeds required minimums and ensures statistical analysis's reliability. Also, we conducted a post-hoc statistical power analysis. The average effect size for the relationships included in the proposed model was 0.248 , which with an

alpha level of 0.05 and four predictors provided a statistical power of 0.762 , well close to the 
accepted threshold of 0.800 . The results of two statistical power analyses above confirm that the nonsignificant effects of the empirical analysis are not because of the sample size.

We tested our hypotheses using the Partial Least Squares SEM (PLS-SEM) through ADANCO 2.2.0 because of its advantages to processing simultaneously latent reflective and formative variables, samples in small size, relying less on distributional assumptions, and importantly, “identifying key 'driver’ constructs” via a complex research model such as ours (Hair et al., 2011; Henseler \& Dijkstra, 2015). Following PLS-SEM guidelines (Fassott et al., 2016; Henseler et al., 2016; van Riel et al., 2017), we performed a three-stage approach to evaluate our model: (1) assessment of global model fit; (2) assessment of the measurement model, and (3) assessment of structural model. To find significance of indices, we used the bootstrap procedure, with nonparametric resampling 5000 replications to achieve the standard error of the estimates.

\section{Assessment of overall goodness of model}

We evaluated the overall goodness of model fit of our saturated model by examining the standardized root mean squared residual (SRMR), unweighted least squares (ULS) discrepancy ( $\mathrm{d}_{\mathrm{ULS}}$ ), and geodesic discrepancy $\left(\mathrm{d}_{\mathrm{G}}\right)$ (Henseler et al., 2016). The lower values suggest a better fit of the proposed model. Table 2 shows that the results for confirmatory composite analysis provide empirical support for the structure of our composite constructs at first- and second-order levels: the SRMR value was $0.047($ HI95 $=0.051)$ and $0.043($ HI95 $=0.053)$, well below the common cut-off threshold of 0.08 ; the values of $\mathrm{d}_{\mathrm{ULS}}$ was 1.454 (HI95 = 1.724) and 1.113 (HI95 = 1.126), and the $\mathrm{d}_{\mathrm{G}}$ was $1.745($ HI95 = 2.055) and $1.353($ HI95 = 1.662).

\section{Insert Table 2 here}

\section{Assessment of the measurement model}

Once the overall quality of the proposed model has been established, we continue to evaluate assess internal consistency reliability, convergent and discriminant validity of key constructs. 
Indicator reliability. Table 3 shows that three capability constructs have individual indicator reliability values (i.e., loading ${ }^{2}$ ) that are greater than the minimum acceptable level of 0.4 and close to the preferred level of 0.7, except for Metacog_26 and Metacog_27 (0.478 and 0.541, respectively) which had adverse effects on convergent validity and internal consistency reliability and so were deleted. Weights for dependent variables (minimum value 0.206 of Experiment_3) are above 0.2 and bootstrapping results show inter-item significance (Chin, 1998).

\section{Insert Table 3 here}

Internal consistency reliability. To measure the reliability, we uses three measures, namely, Cronbach’s alpha, Dijkstra-Henseler's rhoA $\left(\rho_{\mathrm{A}}\right)$, and Jöreskog's rho $(\rho c)$. From Table 4, the interitem consistency reliability values of Cronbach's alpha range from 0.806 to 0.866 , which above the threshold of 0.7 as suggested by Nunnally (1978). In addition, the most consistent reliability Dijkstra- Henseler's rho $\left(\rho_{\mathrm{A}}\right)$ - that measure for PLS construct scores, also achieved satisfactory reliability value, ranging from 0.799 to 0.869 (Dijkstra \& Henseler, 2015). Also, the Jöreskog's rho $(\rho c)$ (known as composite reliability) values range from 0.829 to 0.870 , which exceeded the recommend value of 0.7 (Nunnally \& Bernstein, 1994). Hence, the overall reliability have achieved satisfactory of high internal consistency reliability.

\section{Insert Table 4 here}

Convergent validity. Based on data results, the constructs’ Average Variance Extracted (AVE) was in the range of 0.653 and 0.833 , which exceeded the recommended value of 0.5 (Fornell \& Larcker, 1981). Therefore, our measurement model had adequate convergent validity.

Internal consistency and convergent validity are not applied to formative variables (Bollen and Lennox 1991). Instead, to demonstrate construct validity, we tested for multicollinearity using the variance inflation factor (VIF) (Diamantopoulos \& Winklhofer 2001). The results did not indicate any problems about our only formative construct; the VIF values were well below the cut-off value 
of 5 (Table 3). We also checked the condition indices to identify multicollinearity, and all values were less than 30 (Hair et al. 2011). By applying a bootstrapping procedure, we established the significance of the index weights. We tested for nomological validity by linking each index to the constructs it was expected to link with; the direction of the relationships was reasonable in the context of our proposed model (Diamantopoulos \& Winklhofer 2001). Finally, the correlations between constructs did not raise any concern (see Table 5 in next section).

Discriminant validity. To assess discriminant validity, we used both Fornell-Larcker criterion (FL) and Heterotrait-Monotrait ratio of correlations (HTMT). The FL criterion compares the square root of AVE in each latent (reflective) variable with latent variable correlations. Our data suggests that the square root of each construct's AVE was greater than its highest correlation with any other constructs. The correlation matrix in Table 4 shows that discriminant validity was thus established for all constructs. Next, to assess if the construct is truly distinct from other constructs (Henseler et al., 2015), we proceed to test HTMT values. Our study-wide maximum HTMT is 0.764, which is below the strictest threshold of 0.85 , and thus confirms the discriminant validity of measurement.

\section{Estimation of the structural model}

After establishing reliability and validity, we assessed the structural model by re-sampling about 200 times to reach the number of 5000 samples for bootstrapping (Hair et al., 2011).

Collinearity. We first computed VIF values to examine the collinearity. The result showed that VIF values for all exogenous constructs (e.g., three capabilities and three supports) ranged between 2.817 (consultancy support) and 4.984 (networking capability), indicating that the results were not negatively affected by collinearity as all were less than 5 (Hair et al., 2011). Besides, Table 5 reports the correlations among all hypothesized and control variables in this study. Except within-construct correlations, inter-construct correlations are well below 0.65 threshold, suggesting that our estimations are not biased by the multicollinearity issue (Tabachnick \& Fidell, 1996). 


\section{Insert Table 5 here}

Coefficient of determination $\left(R^{2}\right)$. The $\mathrm{R}^{2}$ value of the endogenous construct is a measure of the variance explained in the model's predictive accuracy. According to Hair et al. (2011), $\mathrm{R}^{2}$ values of $0.75,0.50$, and 0.25 may be considered substantial, moderate, and weak, respectively. Results for our dependent variable - LIE - had a high $\mathrm{R}^{2}$ value of 0.754 (see Model 7 in Table 6). Considering the possibility of extrinsic factors and alternatives, the $\mathrm{R}^{2}$ values are fairly good.

\section{Insert Table 6 here}

Path coefficients. Model 7 in Table 6 presents the direct effects of the three capabilities on the LIE. The $\mathrm{R}^{2}$ indicated that the three capabilities explained $25.2 \%, 33.6 .7 \%, 33.6 \%$ of the variance in the dependent variable of LIE, respectively. Bootstrapping results revealed positive and significant effects of three capabilities on LIE. Networking capability had the strongest and positive effect on LIE ( $\beta=0.336, p<0.01)$, followed by learning agility $(\beta=0.331, p<0.01)$, and metacognitive capability $(\beta=0.252, p<0.01)$. Therefore, H1, H2, and H3 were supported. Besides, the $f^{2}$ values in our hypothesized significant relationships ranged from 0.238 to 0.260 (see Table 6) (values below 0.020 , above 0.150 , and above 0.350 represent weak, medium, and strong effect sizes). The results indicate that our structural model shows good explanatory power.

Moderating effects. Given that our dependent variable was modeled as composite factor, and to avoid multicollinearity issues, we adopted a two-stage approach suggested by Fassott and Henseler (2016) to estimate moderating effects for each of our three moderators. In the first stage, path models comprising direct effects were run to calculate construct scores of the independent and moderating variables. In the second stage, the interaction terms were built as the product term of the extracted construct scores from the first step of each moderator with the independent variable. Table 6 presents the results of our analysis. Model 1, 3, 5 introduce the additional direct effect of three supports on LIE, while Model 2 includes the interaction term to measure the moderating effect of 
consultancy support on the relationship between metacognitive capability and LIE to test H4a. The results reveal that consultancy support does not moderates the metacognitive capability-LIE relationship $(\beta=0.044, p>0.05)$, thus rejecting H4a. At this, high metacognitively aware individuals tend to be more confident in their own judgments, inferences, and strategic decisions. One could also speculate that metacognitive skills through mainly systemic training (Haynie et al., 2010; Kudesia, 2019; Schraw \& Dennison, 1994), is thus more deeply engrained so that it is not easily affected by concrete consultancies offered by local agencies. Similarly, Model 4 tests H4b by introducing the moderation effects of networking support on the networking capability-LIE relationship. Our findings confirm H4b by indicating the positive moderating effect of networking support $(\beta=0.283, p<0.01)$. Finally, Model 5 tests effects of facility support on the learning agilityLIE relationship ( $\beta=0.225, p<0.05)$, also confirming our expectation of H4c.

\section{DISCUSSION}

What driver innovative firms' LIE process effectively? We addressed this question by conceptualizing LIE as a strategic innovation process in which innovative firms together with key partners experiment with complex innovations in local small-scale societies. Our results suggest that a capability portfolio of high levels of metacognitive capability, networking capability, and learning agility contribute to high LIE performance. Further, LIE performance can be strengthened by use of specific local innovation supports. Based on these results, we contribute to the existing literature in two major ways.

\section{Theoretical contribution}

Our first contribution is that we extend the TMT capability portfolio perspective to understand the phenomenon of new ecosystem birth. Prior research has mainly demonstrated the relevance of LIE and the success of new ecosystem birth (e.g., Han et al., 2018; Mahmoud-Jouini \& Charue-Duboc, 
2017; Pekkarinen et al., 2020; von Pechmann et al., 2015). Our study examines the underlying mechanisms why some innovative focal firms are better able to implement LIE activities than others. To do so, we extend the dominant literature that studies innovation ecosystem birth on the ecosystem level (Clarysse et al., 2014; Dattée et al., 2018; Ganco et al., 2020; Hannah \& Eisenhardt, 2018; Jacobides et al., 2018; Kashan \& Mohannak, 2017; Rong et al., 2015; Thomas \& Autio, 2014). Because focal firms shoulder the major responsibility of, and therefore their core capability portfolio is key to, ecosystem development, we argue that heterogeneity of focal firms' capability portfolio at the TMT level can first explain differences in LIE across different focal firms, which in turn probably explain the discrepancies of success rate of new ecosystem birth. In this way, we answer calls for more insights into how focal firms' capabilities enable new innovation ecosystem birth (Cao et al., 2020; Thomas \& Autio, 2020; Velu, 2015; Walrave et al., 2018). Overall, our nuanced understanding of how TMT capability portfolio influences on LIE process suggests that future research designs should take the multi-level view to uncover ecosystem birth process.

Our second contribution is to the "bottom-up" entrepreneurial ecosystem literature. Most prior research on entrepreneurial ecosystem has evidenced the role of heterogenous, synergetic regional innovation resources in spawning high-growth firms (Cohen, 2006; Mason \& Brown, 2014; Spigel, 2017). In contrast to such "top-down" approach, our study centers on the "bottom-up" approach, focusing on the ways of managers utilizing their ecosystems to get the resources, knowledge, and support they need (Spigel, 2018). Specifically, our study explicates that the flow of the entrepreneurial ecosystem's material-relevant resources into innovative firms improved their capability levels. And strengthened capabilities cause higher LIE performance. However, given the contextual nature of LIE process, managers active social embeddedness into regional ecosystems could pay off instantly when structured innovation resources have direct complementary effect on TMT capabilities. Regarding to this unidirectional relation, our findings reveal that managers' 
higher-order capabilities are hardly influenced by regional cognitive innovation resources. Thus, future research with longitudinal data could help unfold much complex connections between innovation resources, capabilities, and innovation practices.

\section{Managerial implication}

Our study provides three guidelines for managers. Managers should shift their foci to having a higher-level cognitive process when analyzing various feedbacks from experimentation activities. Treating on-site feedbacks directly and superficially has possible risks of misinterpretation and myopia. Managers should instead have a macroscopic view on LIE process by knowing their own thinking more clear, such as the overall way of analyzing beliefs, general risk inclination, or other cognitive preference (such as relying on intuition); also, they should know how others think and, especially, weaknesses and strengths of others' thinking mode and habits. So managers as cognitively founded philosophers are able to align the presence and the future, balance the part and the whole, of the LIE. Managers should also keep in mind the trained nature of such higher-order cognitions, since our results suggest that other short-term cognition inputs (e.g., consultancies) show no significant impacts on the metacognition-LIE relationship. Therefore, one way out of solving such defect is to involve senior managers who are argued to have a satisfied breadth and depth of metacognitive knowledge and experiences during LIE process (Mitchell et al., 2011; Najmaei \& Sadeghinejad, 2019); the other way is to design special training programs for top managers to (re)shape their formation of information processing strategies during uncertain and complex situations (Kudesia, 2019).

Next, managers should also notice that a minimum but viable network of value complementors is fundamental to LIE activities. However, notice also that such collaborative network is not static but dynamic because LIE process in early and later periods need different key value creators. This strategic requirement poses a great challenge for managers of SMEs who suffer a low level of social 
capital (Colombo \& Grilli, 2005; Giudici et al., 2018). To alleviate such drawback, a nonlinear solution should always be considered during LIE activities. That is, managers should scan or approach regional powerful institutional agencies (e.g., industry association), and leverage all possible networking opportunities. Though such proactive actions, regional social capital owned by local entrepreneurial third-parties could be smoothly transferred to SMEs. Thanks to the rendered legitimacy and endorsement from them, they could always have viable products or services as they could approach “uncommon” complementary partners more readily, ensure partners’ long-term commitment, solve collaborative conflict effectively, and even sever unfavorable ties creatively.

Finally, on the operational side, managers should recognize the availability and integration of various enabling facilities at places which they undertake LIE. Time and resource constraints require managers to take the lead to detect and respond to technical problems which emerged frequently during early-stage of LIE process. If integrated properly and timely, the innovation facilities, devices, platforms as a system can offset the low problem-sensing and problem-solving speed, flexibility, and efficiency. Meanwhile, the aim of agile learning is to defend the leadership in LIE process. Managers should thus try ways to crystalize their new tacit knowledge on innovations to avoid appropriation risks and opportunisms. To this aim, new acquired knowledge should be framed timely as patents, license, and other form of technology protection. It of course entails managers' intellectual property management alertness during the whole LIE process.

\section{Limitations and future directions}

Two limitations call for further research. First, because we focus on explaining variations in LIE pertaining to new-to-the-market innovations that are complex and systemic, our research results face applicability problems. One would question the extent to which our empirical findings could be applied to different institutional and cultural setting since our sample comes from an emerging economy (China). Moreover, applicability issue arises when comes to disruptive innovations (e.g., 
blockchain-related services). Localized experimentation process for this type of innovation might ask for firms' considerable resources, attention and time given its technological complexity, and huge societal uncertainties on the society and legal system. Hence, promoting higher LIE performance might need a strong portfolio of managerial dynamic capabilities and moreover strong supportive socio-spatial environments. Together, based on the capability portfolio perspective and regional innovation system literature we take in this study, scholars have opportunities to check our framework’s applicability in different institutional and industrial settings.

Second, in spite of this study presented interesting results about the capability antecedents of LIE process, limitations exist that we (1) focus on three TMT-level capabilities, and (2) view three capabilities as exogenous factors. One would question if there are other managerial dynamic capabilities enabling high level of LIE performance, not limited to our proposed three. One would also question if there are some interactions between different capabilities (Adner \& Helfat, 2003). Such endogenous perspective lies in the basis that during LIE activities from early to later stages, different capabilities might reinforce each other, thereby promoting higher LIE performance. Therefore, future studies could combine longitudinal case studies and fsQCA methods to mitigate these drawbacks. By using comparable cases, researchers could not only know a comprehensive portfolio of capabilities which play positive role in LIE performance, but know further how capabilities interact with rich process data. Current research results could be shaped by researchers since they can test the direct effects of inter-organizational level capabilities on LIE by using selfreported data from multiple informants. Through fsQCA analysis, researchers have deeper insights regarding to which bundles of capabilities have the most positive effects on LIE performance.

\section{CONCLUSION}

By what means can innovative firms have high performance of LIE process, which is important for the successful development of new complex innovations? Whereas previous research has already 
illustrated LIE's main principles, we take a further step to explain what organizational capabilities and local environment to predict higher LIE performance. Our PLS-SEM results suggest that managers’ capability portfolio (including metacognition, networking capability, and learning agility) and two types of material-relevant innovation supports (i.e., network activities and facility) matter significantly. This study highlights benefits of firm-level capability perspective to better understand new ecosystem birth phenomena under complex small-scale socio-spatial contexts.

\section{REFERENCES}

Acquaah, M. (2007). Managerial social capital, strategic orientation, and organizational performance in an emerging economy. Strategic Management Journal, 28(12), 1235-1255.

Adner, R. (2012). The wide lens: A new strategy for innovation. London: Penguin.

Adner, R., \& Helfat, C. E. (2003). Corporate effects and dynamic managerial capabilities. Strategic Management Journal, 24(10), 1011-1025.

Ansell, C. K., \& Bartenberger, M. (2016). Varieties of experimentalism. Ecological Economics, 130, 64-73.

Atuahene-Gima, K., \& Wei, Y. (2011). The vital role of problem-solving competence in new product success. Journal of Product Innovation Management, 28(1), 81-98.

Autio, E., Kenney, M., Mustar, P., Siegel, D., \& Wright, M. (2014). Entrepreneurial innovation: The importance of context. Research policy, 43(7), 1097-1108.

Autio, E., Nambisan, S., Thomas, L. D., \& Wright, M. (2018). Digital affordances, spatial affordances, and the genesis of entrepreneurial ecosystems. Strategic Entrepreneurship Journal, 12(1), 72-95.

Avolio, B. J., Yammarino, F. J., \& Bass, B. M. (1991). Identifying common methods variance with data collected from a single source: An unresolved sticky issue. Journal of Management, 17(3), 571-587.

Basole, R. C., Park, H., \& Barnett, B. C. (2015). Coopetition and convergence in the ICT ecosystem. Telecommunications Policy, 39(7), 537-552.

Brislin, R. W. (1970). Back-translation for cross-cultural research. Journal of Cross-cultural Psychology, 1(3), 185-216.

Bollen, K., \& Lennox, R. (1991). Conventional wisdom on measurement: A structural equation perspective. Psychological Bulletin, 110(2), 305-314.

Cao, X., Ouyang, T., Balozian, P., \& Zhang, S. (2020). The Role of Managerial Cognitive Capability in Developing a Sustainable Innovation Ecosystem: A Case Study of Xiaomi. Sustainability, 12(17), 71-76.

Carmeli, A., Zivan, I., Gomes, E., \& Markman, G. D. (2017). Underlining micro socio-psychological mechanisms of buyer-supplier relationships: Implications for inter-organizational learning agility. Human Resource Management Review, In Press.

Carpenter, M. A., Geletkanycz, M. A., \& Sanders, W. G. (2004). Upper echelons research revisited: Antecedents, elements, and consequences of top management team composition. Journal of Management, 30(6), 749-778.

CBRE, 2019 (October, 2020). Retrieved from https://www.cbre.com/research-and-reports/Asia-PacificMajor-Report---Programming-Asia-Pacific-Tech-Cities-as-Global-Tech-Hubs-April-2019.

Chesbrough,H.W., \& D. J. Teece (1996). 'When is virtual virtuous?: Organizing for innovation,' Harvard Business Review, 74, 65-73.

Cho, Y. S., \& Linderman, K. (2019). Metacognition-based process improvement practices. International Journal of Production Economics, 211, 132-144.

Clarysse, B., Wright, M., Bruneel, J., \& Mahajan, A. (2014).Creating value in ecosystems: crossing the chasm between knowledge and business ecosystems. Research Policy, 43, 1164-1176. 
Cohen, B. (2006). Sustainable valley entrepreneurial ecosystems. Business Strategy and the Environment, 15(1), 1-14.

Colombo, M. G., \& Grilli, L. (2005). Founders' human capital and the growth of new technology-based firms: A competence-based view. Research Policy, 34(6), 795-816.

Cooper, R. G., \& Kleinschmidt, E. J. (1994). Determinants of timeliness in product development. Journal of Product Innovation Management, 11(5), 381-396.

Cunningham, J. B., \& McCrum-Gardner, E. (2007). Power, effect and sample size using GPower: Practical issues for researchers and members of research ethics committees. Evidence Based Midwifery, 5(4), 132136.

Dattée, B., Alexy, O., \& Autio, E. (2018). Maneuvering in poor visibility: How firms play the ecosystem game when uncertainty is high. Academy of Management Journal, 61(2), 466-498.

de Vasconcelos Gomes, L. A., Salerno, M. S., Phaal, R., \& Probert, D. R. (2018). How entrepreneurs manage collective uncertainties in innovation ecosystems. Technological Forecasting and Social Change, 128, 164-185.

DeRue, D. S., Ashford, S. J., \& Myers, C. G. (2012). Learning agility: In search of conceptual clarity and theoretical grounding. Industrial and Organizational Psychology, 5(3), 258-279.

Di Benedetto, C. A. (1999). Identifying the key success factors in new product launch. Journal of Product Innovation Management, 16(6), 530-544.

Diamantopoulos, A., \& Winklhofer, H. M. (2001). Index construction with formative indicators: an alternative to scale development. Journal of Marketing Research, 38, 269-277.

Diestre, L., \& Rajagopalan, N. (2012). Are all 'sharks' dangerous? new biotechnology ventures and partner selection in R\&D alliances. Strategic Management Journal, 33(10), 1115-1134.

Doblinger, C., Surana, K., \& Anadon, L. D. (2019). Governments as partners: The role of alliances in US cleantech startup innovation. Research Policy, 48(6), 1458-1475.

Dolan, R. J., \& Matthews, J. M. (1993). Maximizing the utility of customer product testing: beta test design and management. Journal of Product Innovation Management, 10(4), 318-330.

Dougherty, D., \& Dunne, D. D. (2011). Organizing ecologies of complex innovation. Organization Science, 22(5), 1214-1223.

Fassott, G., Henseler, J., \& Coelho, P. (2016). Testing moderating effects in PLS path models with composite variables. Industrial Management \& Data Systems, 116, 1887-1900.

Forkmann, S., Henneberg, S. C., Naude, P., \& Mitrega, M. (2016). Supplier relationship management capability: a qualification and extension. Industrial Marketing Management, 57, 185-200.

Fornell, C., \& Larcker, D. F. (1981). Evaluating structural equation models with unobservable variables and measurement error. Journal of Marketing Research, 18(1), 39-50.

Furr, N., \& Shipilov, A. (2018). Building the right ecosystem for innovation. MIT Sloan Management Review, 59(4), 59-64.

Ganco, M., Kapoor, R., \& Lee, G. K. (2020). From rugged landscapes to rugged ecosystems: Structure of interdependencies and firms' innovative search. Academy of Management Review, 45(3), 646-674.

Gardet, E., \& Mothe, C. (2011). The dynamics of coordination in innovation networks. European Management Review, 8(4), 213-229.

Gassmann, O., Zeschky, M., Wolff, T., \& Stahl, M. (2010). Crossing the industry-line: breakthrough innovation through cross-industry alliances with ‘non-suppliers'. Long Range Planning, 43(5-6), 639-654.

Giudici, A., Reinmoeller, P., \& Ravasi, D. (2018). Open-system orchestration as a relational source of sensing capabilities: Evidence from a venture association. Academy of Management Journal, 61(4), 1369-1402.

Goodhue, D. L., Lewis, W., \& Thompson, R. (2012). Does PLS have advantages for small sample size or non-normal data?. MIS Quarterly, 981-1001.

Grashof, N., Hesse, K., \& Fornahl, D. (2019). Radical or not? The role of clusters in the emergence of radical innovations. European Planning Studies, 27(10), 1904-1923.

Gruner, K. E., \& Homburg, C. (2000). Does customer interaction enhance new product success?. Journal of Business Research, 49(1), 1-14.

Hair, J. F., Ringle, C. M., \& Sarstedt, M. (2011). PLS-SEM: Indeed a silver bullet. Journal of Marketing Theory and Practice, 19(2), 139-152. 
Hallen, B. L., \& Eisenhardt, K. M. (2012). Catalyzing strategies and efficient tie formation: How entrepreneurial firms obtain investment ties. Academy of Management Journal, 55(1), 35-70.

Hambrick, D. C., \& Mason, P. A. (1984). Upper echelons: The organization as a reflection of its top managers. Academy of Management Review, 9(2), 193-206.

Hampel, C., Perkmann, M., \& Phillips, N. (2020). Beyond the lean start-up: experimentation in corporate entrepreneurship and innovation. Innovation, 22, 1- 11.

Hanlon, D., \& Saunders, C. (2007). Marshaling resources to form small new ventures: Toward a more holistic understanding of entrepreneurial support. Entrepreneurship Theory and Practice, 31(4), 619-641.

Han, J., Shah-Zhou, H., Lowik, S. J. A., \& de Weerd, P. (2018). Building and sustaining the emerging ecosystems by focal new ventures: evidence from the bike-sharing industry in China. Working Paper.

Hannah, D. P., \& Eisenhardt, K. M. (2018). How firms navigate cooperation and competition in nascent ecosystems. Strategic Management Journal, 39(12), 3163-3192.

Haynie, J. M., \& Shepherd, D. A. (2009). A measure of adaptive cognition for entrepreneurship research. Entrepreneurship Theory and Practice, 33(3), 695-714.

Haynie, J. M., Shepherd, D. A., Mosakowski, E., \& Earley, P. C. (2010). A situated metacognitive model of the entrepreneurial mindset. Journal of Business Venturing, 25(2), 217-229.

Haynie, J. M., Shepherd, D. A., \& Patzelt, H. (2012). Cognitive adaptability and an entrepreneurial task: The role of metacognitive ability and feedback. Entrepreneurship Theory and Practice, 36(2), 237-265.

Helfat, C. E., \& Peteraf, M. A. (2015). Managerial cognitive capabilities and the microfoundations of dynamic capabilities. Strategic Management Journal, 36(6), 831-850.

Henseler, J. and Dijkstra, T.K. (2015), “ADANCO 2.0.1”, Composite Modeling, Kleve, available at: www.compositemodeling.com.

Henseler, J., Hubona, G., \& Ray, P. A. (2016). Using PLS path modeling in new technology research: updated guidelines. Industrial Management \& Data Systems, 116, 2-20.

Hottenrott, H., \& Lopes-Bento, C. (2016). R\&D partnerships and innovation performance: Can there be too much of a good thing?. Journal of Product Innovation Management, 33(6), 773-794.

Hyysalo, S., \& Hakkarainen, L. (2014). What difference does a living lab make? Comparing two health technology innovation projects. CoDesign, 10(3-4), 191-208.

Jacobides, M. G., Cennamo, C., \& Gawer, A. (2018). Towards a theory of ecosystems. Strategic Management Journal, 39(8), 2255-2276.

Kashan, A. J., \& Mohannak, K. (2017). The Role of Knowledge Integration in Capability Development and Emergence of Innovation Ecosystem. International Journal of Innovation and Technology Management, 14(5), 1-18.

Klompmaker, J. E. (1976). Test Marketing in New Product Development. Harvard Business Review, 54(3), 128-138.

Kock, N. (2015). Common method bias in PLS-SEM: A full collinearity assessment approach. International Journal of e-Collaboration, 11(4), 1-10.

Kaufmann, A., \& Tödtling, F. (2002). How effective is innovation support for SMEs? An analysis of the region of Upper Austria. Technovation, 22(3), 147-159.

Kraiczy, N. D., Hack, A., \& Kellermanns, F. W. (2015). What makes a family firm innovative? CEO risktaking propensity and the organizational context of family firms. Journal of Product Innovation Management, 32(3), 334-348.

Kudesia, R. S. (2019). Mindfulness as metacognitive practice. Academy of Management Review, 44(2), 405423.

Lavie, D. (2007). Alliance portfolios and firm performance: A study of value creation and appropriation in the US software industry. Strategic Management Journal, 28(12), 1187-1212.

Liu, G., \& Rong, K. (2015). The nature of the co-evolutionary process: Complex product development in the mobile computing industry's business ecosystem. Group \& Organization Management, 40(6), 809-842.

Lorenz, M. P., Ramsey, J. R., \& Richey Jr, R. G. (2018). Expatriates’ international opportunity recognition and innovativeness: The role of metacognitive and cognitive cultural intelligence. Journal of World Business, 53(2), 222-236. 
Lütjen, H., Schultz, C., Tietze, F., \& Urmetzer, F. (2019). Managing ecosystems for service innovation: A dynamic capability view. Journal of Business Research, 104, 506-519.

Mahmoud-Jouini, S. B., \& Charue-Duboc, F. (2017). Experimentations in emerging innovation ecosystems: specificities and roles. The case of the hydrogen energy fuel cell. International Journal of Technology Management, 75(1-4), 28-54.

Mason, C., \& Brown, R. (2014). Entrepreneurial ecosystems and growth oriented entrepreneurship. Final report to OECD, Paris, 30(1), 77-102.

Mitchell, J., Shepherd, D., \& Sharfman, M.P. (2011). Erratic strategic decisions: when and why managers are inconsistent in strategic decision making. Strategic Management Journal, 32, 683-704.

Mitrega, M., Forkmann, S., Ramos, C., \& Henneberg, S. C. (2012). Networking capability in business relationships-Concept and scale development. Industrial Marketing Management, 41(5), 739-751.

Mitręga, M., Forkmann, S., Zaefarian, G., \& Henneberg, S. (2017). Networking capability in supplier relationships and its impact on product innovation and firm performance. International Journal of Operations \& Production Management, 37, 577-606.

Mor, S., Morris, M. W., \& Joh, J. (2013). Identifying and training adaptive cross-cultural management skills: The crucial role of cultural metacognition. Academy of Management Learning \& Education, 12(3), 453475.

Najmaei A., \& Sadeghinejad Z. (2019). Metacognition, Entrepreneurial Orientation, and Firm Performance: An Upper Echelons View. In: Caputo A., Pellegrini M. (eds) The Anatomy of Entrepreneurial Decisions. Contributions to Management Science. Springer, Cham.

Nambisan, S., \& Baron, R. A. (2013). Entrepreneurship in innovation ecosystems: Entrepreneurs' selfregulatory processes and their implications for new venture success. Entrepreneurship Theory and Practice, 37(5), 1071-1097.

Noel, L., \& Sovacool, B. K. (2016). Why did better place fail?: range anxiety, interpretive flexibility, and electric vehicle promotion in Denmark and Israel. Energy Policy, 94, 377-386.

Oskam, I., Bossink, B., \& de Man, A. P. (2020). Valuing value in innovation ecosystems: How cross-sector actors overcome tensions in collaborative sustainable business model development. Business \& Society. https://doi.org/10.1177/0007650320907145.

Overby, E., Bharadwaj, A., \& Sambamurthy, V. (2006). Enterprise agility and the enabling role of information technology. European Journal of Information Systems, 15(2), 120-131.

Paquin, R. L., \& Howard-Grenville, J. (2013). Blind dates and arranged marriages: Longitudinal processes of network orchestration. Organization Studies, 34(11), 1623-1653.

Parente, R., Rong, K., Geleilate, J. M. G., \& Misati, E. (2019). Adapting and sustaining operations in weak institutional environments: A business ecosystem assessment of a Chinese MNE in Central Africa. Journal of International Business Studies, 50(2), 275-291.

Patton, D., \& Kenney, M. (2005). The spatial configuration of the entrepreneurial support network for the semiconductor industry. R\&D Management, 35(1), 1-16.

Pekkarinen, S., Tuisku, O., Hennala, L., \& Melkas, H. (2020). Robotics in Finnish welfare services: dynamics in an emerging innovation ecosystem. European Planning Studies, 28(8), 1513-1533.

Pidun, U., Reeves, M., \& Schüssler, M. (2020). How Do You “Design” a Business Ecosystem? Retrieved 12 March 2020 from https://www.bcg.com/publications/2020/how-do-you-designa-businessecosystem.aspx.

Piller, F. T., \& Susumu, O. (2006). Reducing the risks of new product development. MIT Sloan Management Review, 47(2), 65-71.

Prince, K., Barrett, M., \& Oborn, E. (2014). Dialogical strategies for orchestrating strategic innovation networks: The case of the Internet of Things. Information and Organization, 24(2), 106-127.

Rong, K., Wu, J., Shi, Y., \& Guo, L. (2015). Nurturing business ecosystems for growth in a foreign market: Incubating, identifying and integrating stakeholders. Journal of International Management, 21(4), 293308.

Sambamurthy, V., Bharadwaj, A., \& Grover, V. (2003). Shaping agility through digital options: Reconceptualizing the role of information technology in contemporary firms. MIS quarterly, 237-263. 
Seidl, D., \& Werle, F. (2018). Inter-organizational sensemaking in the face of strategic meta-problems:

Requisite variety and dynamics of participation. Strategic Management Journal, 39(3), 830-858.

Schraw, G., \& Dennison, R. S. (1994). Assessing metacognitive awareness. Contemporary Educational Psychology, 19(4), 460-475.

Schuhmacher, M., Kuester, S., \& Hultink, E.J. (2018). Appetizer or main course: Early market vs. majority market go-to-market strategies for radical innovations. Journal of Product Innovation Management, 35, 106-124.

Spigel, B. (2017). The Relational Organization of Entrepreneurial Ecosystems. Entrepreneurship Theory \& Practice, 41(1), 49-72.

Spigel, B. (2018), "Envisioning a new research agenda for entrepreneurial ecosystems: top-down and bottomup approaches”, in Katz, J.A. and Corbett, A.C. (Eds), Advances in Entrepreneurship, Firm Emergence, and Growth: Reflections and Extensions on Key Papers of the First Twenty-Five Years of Advances, Emerald Publishing Limited, Bingley, 127-147.

Stanko, M. A., Molina-Castillo, F. J., \& Munuera-Aleman, J. L. (2012). Speed to market for innovative products: blessing or curse?. Journal of Product Innovation Management, 29(5), 751-765.

Tabachnick, B. G., \& Fidell, L. S. (1996). Using multivariate statistics New York Harper Collins.

Talke, K., Salomo, S., \& Kock, A. (2011). Top management team diversity and strategic innovation orientation: The relationship and consequences for innovativeness and performance. Journal of Product Innovation Management, 28(6), 819-832.

Teece, D. J. (2007). Explicating dynamic capabilities: the nature and microfoundations of (sustainable) enterprise performance. Strategic Management Journal, 28(13), 1319-1350.

Thomke, S. H. (1998). Managing experimentation in the design of new products. Management Science, 44(6), 743-762.

Thomke, S. (2003). Experimentation Matters: Unlocking the Potential of New Technologies for Innovation, Harvard Business School Press, Cambridge, MA.

Thomas, L. D. W., \& Autio, E. (2014). The processes of ecosystem emergence. Working Paper, Imperial College Business School, University of London, July.

Thomas, L. D. W., \& Autio, E. (2020). Innovation ecosystems in management: An organizing typology. In Oxford Encyclopedia of business and management, Oxford: Oxford University Press.

Vaaland, T. I., Haugland, S. A., \& Purchase, S. (2004). Why do business partners divorce? The role of cultural distance in inter-firm conflict behavior. Journal of Business To Business Marketing, 11(4), 1-21.

Velu, C. (2015). Knowledge management capabilities of lead firms in innovation ecosystems. AMS review, 5(3-4), 123-141.

von Pechmann, F., Midler, C., Maniak, R., \& Charue-Duboc, F. (2015). Managing systemic and disruptive innovation: lessons from the Renault Zero Emission Initiative. Industrial and Corporate Change, 24(3), 677-695.

van Riel, A. C., Henseler, J., Kemény, I., \& Sasovova, Z. (2017). Estimating hierarchical constructs using consistent partial least squares. Industrial Management \& Data Systems, 177, 459-477.

Walrave, B., Talmar, M., Podoynitsyna, K. S., Romme, A. G. L., \& Verbong, G. P. (2018). A multi-level perspective on innovation ecosystems for path-breaking innovation. Technological Forecasting and Social Change, 136, 103-113.

Walter, A., Auer, M., \& Ritter, T. (2006). The impact of network capabilities and entrepreneurial orientation on university spin-off performance. Journal of Business Venturing, 21(4), 541-567.

Zahra, S. A., \& Nambisan, S. (2012). Entrepreneurship and strategic thinking in business ecosystems. Business Horizons, 55(3), 219-229.

Zahra, S. A., Wright, M., \& Abdelgawad, S. G. (2014). Contextualization and the advancement of entrepreneurship research. International Small Business Journal, 32(5), 479-500. 
Figure 1. Conceptual model.

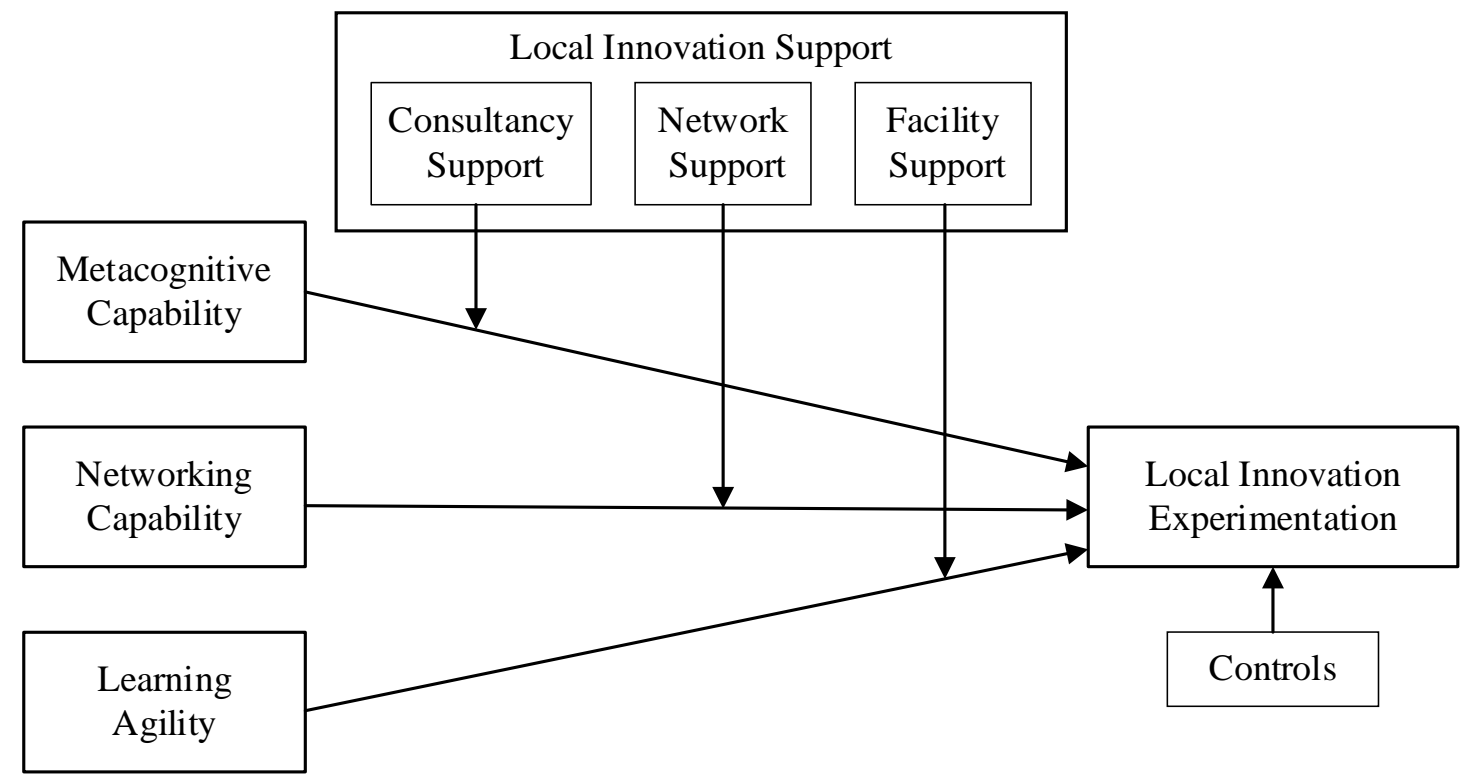

Table 1. Descriptive statistics $(\mathrm{N}=111)$.

\begin{tabular}{llll}
\hline Item & Scale & $\mathbf{n}$ & $\mathbf{\%}$ \\
\hline Innovation Hub & Four Innovation Hubs & 60 & $54.1 \%$ \\
& Others & 51 & $45.9 \%$ \\
Company Age & $\leqslant 2000$ & 30 & $27.0 \%$ \\
& $2001-2005$ & 9 & $8.1 \%$ \\
& $2006-2010$ & 15 & $13.5 \%$ \\
Size & $2011-2015$ & 29 & $26.1 \%$ \\
& $2015-C u r r e n t$ & 28 & $25.2 \%$ \\
& $\leqslant 10$ & 6 & $5.4 \%$ \\
Industry & $11-50$ & 22 & $19.8 \%$ \\
& $51-100$ & 14 & $12.6 \%$ \\
& $101-500$ & 20 & $18.0 \%$ \\
& $\geqslant 501$ & 49 & $44.1 \%$ \\
& Renewable energy and new material & 32 & $28.8 \%$ \\
& Electric vehicle and mobile Internet & 27 & $24.3 \%$ \\
& Next-generation mobile communication & 17 & $15.3 \%$ \\
& technology & & \\
& Manufacturing and artificial intelligence & 16 & $14.4 \%$ \\
& (AI) & & \\
& Biomedicine and devices & 7 & $6.3 \%$ \\
& Others & 12 & $10.9 \%$ \\
\hline
\end{tabular}

Table 2. Results for the confirmatory composite analysis.

\begin{tabular}{lllllll}
\hline \multirow{2}{*}{ Discrepancy } & \multicolumn{2}{l}{ First-order level } & & \multicolumn{3}{c}{ Second-order level } \\
\cline { 2 - 7 } & Value & HI95 & Conclusion & Value & HI95 & Conclusion \\
\hline SRMR & 0.047 & 0.051 & Supported & 0.043 & 0.053 & Supported \\
$\mathrm{d}_{\mathrm{ULS}}$ & 1.454 & 1.724 & Supported & 1.113 & 1.126 & Supported \\
$\mathrm{d}_{\mathrm{G}}$ & 1.745 & 2.055 & Supported & 1.353 & 1.662 & Supported \\
\hline
\end{tabular}


Table 3. Factor Loadings and weights for measured constructs.

\begin{tabular}{|c|c|c|c|c|c|c|}
\hline Item Abbreviation & Metacog & Network & Learn & Support1 & Support2 & Support3 \\
\hline Metacog_11 & 0.822 & 0.724 & 0.660 & 0.635 & 0.614 & 0.458 \\
\hline Metacog_12 & 0.797 & 0.712 & 0.624 & 0.632 & 0.598 & 0.480 \\
\hline Metacog_13 & 0.835 & 0.722 & 0.648 & 0.650 & 0.573 & 0.422 \\
\hline Metacog_14 & 0.842 & 0.715 & 0.685 & 0.666 & 0.625 & 0.548 \\
\hline Metacog_15 & 0.858 & 0.750 & 0.686 & 0.622 & 0.626 & 0.560 \\
\hline Metacog_16 & 0.811 & 0.607 & 0.552 & 0.629 & 0.464 & 0.454 \\
\hline Metacog_17 & 0.793 & 0.654 & 0.564 & 0.600 & 0.476 & 0.479 \\
\hline Metacog_18 & 0.788 & 0.637 & 0.629 & 0.585 & 0.571 & 0.514 \\
\hline Metacog_19 & 0.803 & 0.659 & 0.640 & 0.632 & 0.577 & 0.512 \\
\hline Metacog_110 & 0.787 & 0.589 & 0.553 & 0.581 & 0.495 & 0.458 \\
\hline Metacog_111 & 0.845 & 0.653 & 0.595 & 0.616 & 0.544 & 0.503 \\
\hline Metacog_21 & 0.835 & 0.690 & 0.631 & 0.590 & 0.548 & 0.383 \\
\hline Metacog_22 & 0.848 & 0.686 & 0.617 & 0.604 & 0.572 & 0.402 \\
\hline Metacog_23 & 0.849 & 0.724 & 0.647 & 0.616 & 0.612 & 0.440 \\
\hline Metacog_24 & 0.828 & 0.711 & 0.662 & 0.562 & 0.514 & 0.506 \\
\hline Metacog_25 & 0.795 & 0.651 & 0.601 & 0.529 & 0.502 & 0.468 \\
\hline Metacog_28 & 0.806 & 0.438 & 0.351 & 0.496 & 0.374 & 0.346 \\
\hline Network_1 & 0.728 & 0.911 & 0.766 & 0.621 & 0.771 & 0.623 \\
\hline Network_2 & 0.713 & 0.907 & 0.741 & 0.562 & 0.719 & 0.593 \\
\hline Network_3 & 0.721 & 0.904 & 0.748 & 0.609 & 0.736 & 0.543 \\
\hline Network_4 & 0.721 & 0.875 & 0.685 & 0.586 & 0.712 & 0.583 \\
\hline Network_5 & 0.717 & 0.903 & 0.742 & 0.582 & 0.754 & 0.579 \\
\hline Network_6 & 0.736 & 0.910 & 0.777 & 0.585 & 0.753 & 0.585 \\
\hline Network_7 & 0.747 & 0.868 & 0.735 & 0.669 & 0.698 & 0.563 \\
\hline Learn_11 & 0.655 & 0.760 & 0.808 & 0.493 & 0.672 & 0.674 \\
\hline Learn_12 & 0.683 & 0.733 & 0.810 & 0.486 & 0.628 & 0.649 \\
\hline Learn_13 & 0.667 & 0.744 & 0.915 & 0.496 & 0.644 & 0.705 \\
\hline Learn_14 & 0.676 & 0.737 & 0.897 & 0.563 & 0.637 & 0.707 \\
\hline Learn_21 & 0.652 & 0.732 & 0.890 & 0.533 & 0.635 & 0.683 \\
\hline Learn_22 & 0.717 & 0.732 & 0.895 & 0.532 & 0.624 & 0.662 \\
\hline Learn_23 & 0.717 & 0.751 & 0.855 & 0.481 & 0.673 & 0.642 \\
\hline Support_11 & 0.714 & 0.612 & 0.543 & 0.880 & 0.578 & 0.553 \\
\hline Support_12 & 0.648 & 0.572 & 0.502 & 0.892 & 0.499 & 0.444 \\
\hline Support_13 & 0.609 & 0.583 & 0.482 & 0.875 & 0.481 & 0.387 \\
\hline Support_14 & 0.633 & 0.576 & 0.468 & 0.851 & 0.488 & 0.503 \\
\hline Support_21 & 0.602 & 0.801 & 0.681 & 0.538 & 0.813 & 0.525 \\
\hline Support_22 & 0.618 & 0.755 & 0.644 & 0.539 & 0.826 & 0.494 \\
\hline Support_23 & 0.670 & 0.768 & 0.686 & 0.557 & 0.813 & 0.524 \\
\hline Support_24 & 0.589 & 0.727 & 0.611 & 0.507 & 0.799 & 0.468 \\
\hline Support_31 & 0.472 & 0.534 & 0.599 & 0.471 & 0.494 & 0.844 \\
\hline Support_32 & 0.515 & 0.581 & 0.690 & 0.478 & 0.470 & 0.825 \\
\hline Support_33 & 0.545 & 0.584 & 0.694 & 0.478 & 0.512 & 0.817 \\
\hline Support_34 & 0.508 & 0.587 & 0.670 & 0.487 & 0.477 & 0.846 \\
\hline Experiment_1 & \multicolumn{6}{|c|}{0.610 (weight, $\mathrm{VIF}=2.289)$} \\
\hline Experiment_2 & \multicolumn{6}{|c|}{0.305 (weight, VIF = 2.389) } \\
\hline Experiment_3 & \multicolumn{6}{|c|}{0.206 (weight, VIF = 2.762) } \\
\hline Metacog_26 & \multicolumn{6}{|l|}{0.478} \\
\hline Metacog_27 & \multicolumn{6}{|l|}{0.541} \\
\hline
\end{tabular}

Note: Metacognitive capability = Metacog, Networking capability = Network, Learning agility = Learn, Consultancy support = Support1, Network support $=$ Support2, Facility support $=$ Support3, LIE = Experiment; Variance inflation factor =VIF; Metacog_26 and Metacog_27 are two deleted items since their t-values are below the expected significance level ( $\left.p_{\text {two-tailed }}>0.05\right)$. 
Table 4. Reliability and validity of construct measurement.

\begin{tabular}{lllllll}
\hline Constructs & $(\boldsymbol{\rho A})$ & $\mathbf{( \rho c )}$ & $\mathbf{C A}$ & AVE & FL & HTMT \\
\hline Metacognitive capability & 0.869 & 0.870 & 0.866 & 0.653 & 0.589 & 0.758 \\
Networking capability & 0.860 & 0.866 & 0.859 & 0.804 & 0.699 & 0.764 \\
Learning agility & 0.859 & 0.866 & 0.859 & 0.803 & 0.684 & 0.700 \\
Consultancy support & 0.799 & 0.829 & 0.798 & 0.765 & 0.557 & 0.660 \\
Network support & 0.834 & 0.852 & 0.833 & 0.833 & 0.699 & 0.623 \\
Facility support & 0.811 & 0.834 & 0.806 & 0.781 & 0.567 & 0.694 \\
\hline
\end{tabular}

Note: Dijkstra-Henseler's rho = $(\rho A)$; Jöreskog's rho = $(p c) ; C A=$ Cronbach's Alpha; Average Variance Extracted = $(A V E) ;$ Maximum Fornell-Larcker criterion = FL; Maximum Heterotrait-Monotrait ratio of correlations $=$ HTMT.

Table 5. Correlations matrix of the constructs at the second and first-order levels.

\begin{tabular}{|c|c|c|c|c|c|c|c|c|c|c|c|c|c|c|c|c|c|c|c|c|c|c|c|}
\hline Item & 1 & 2 & 3 & 4 & 5 & 6 & 7 & 8 & 9 & 10 & 11.1 & 11.2 & 11.3 & 12.1 & 12.2 & 12.3 & 13 & 13.1 & 13.2 & 14 & 15 & 15.1 & 15.2 \\
\hline $1 \mathrm{Hub}$ & & & & & & & & & & & & & & & & & & & & & & & \\
\hline 2 Age & .190 & & & & & & & & & & & & & & & & & & & & & & \\
\hline 3 Size & .377 & -.536 & & & & & & & & & & & & & & & & & & & & & \\
\hline 4 Layer & .286 & -.508 & .778 & & & & & & & & & & & & & & & & & & & & \\
\hline 5 Department & .160 & -.387 & .617 & .597 & & & & & & & & & & & & & & & & & & & \\
\hline 6 TMT_Number & .188 & -.451 & .744 & .677 & .595 & & & & & & & & & & & & & & & & & & \\
\hline 7 TMT_Industry & .163 & .237 & -.121 & -.148 & -.121 & -.173 & & & & & & & & & & & & & & & & & \\
\hline 8 TMT_Education & -.015 & .046 & .240 & .240 & .311 & .261 & .248 & & & & & & & & & & & & & & & & \\
\hline 9 TMT_Risk & -.038 & -.006 & -.069 & -.109 & .093 & .003 & -.005 & .073 & & & & & & & & & & & & & & & \\
\hline 10 Innovativeness & -.033 & -.034 & -.064 & -.037 & -.037 & -.071 & .070 & -.022 & .105 & & & & & & & & & & & & & & \\
\hline 11.1 Experiment1 & .192 & -.020 & .078 & .045 & .111 & .115 & .021 & .200 & .101 & .066 & & & & & & & & & & & & & \\
\hline 11.2 Experiment2 & .167 & .029 & .058 & .053 & .091 & .035 & .073 & .065 & .094 & .073 & .626 & & & & & & & & & & & & \\
\hline 11.3 Experiment3 & .136 & .075 & .091 & -.027 & .100 & .068 & .095 & .115 & .167 & .157 & .677 & .675 & & & & & & & & & & & \\
\hline 12.1 Consultancy & .560 & -.036 & .137 & .012 & .174 & .081 & .003 & .110 & .187 & .225 & .498 & .483 & .503 & & & & & & & & & & \\
\hline 12.2 Network & .511 & -.104 & .040 & .020 & .128 & .083 & .093 & .215 & .146 & .170 & .591 & .618 & .531 & .483 & & & & & & & & & \\
\hline 12.3 Facility & .586 & -.054 & .148 & .133 & .279 & .215 & -.006 & .285 & .147 & .100 & .568 & .532 & .500 & .482 & .619 & & & & & & & & \\
\hline 13 Metacog & .113 & -.008 & .047 & .035 & .196 & .083 & -.180 & .101 & .249 & .189 & .554 & .457 & .533 & .600 & .572 & .510 & & & & & & & \\
\hline 13.1 Knowledge & .158 & -.129 & .164 & .089 & .237 & .112 & -.217 & .050 & .259 & .180 & .580 & .497 & .536 & .587 & .577 & .503 & .853 & & & & & & \\
\hline 13.2 Experience & .209 & .037 & -.006 & -.024 & .120 & .077 & -.081 & .146 & .240 & .145 & .561 & .475 & .475 & .559 & .565 & .480 & .854 & .788 & & & & & \\
\hline 14 Networking & .058 & -.184 & .123 & .135 & .238 & .187 & -.052 & .270 & .188 & .197 & .665 & .601 & .555 & .555 & .665 & .699 & .609 & .630 & .604 & & & & \\
\hline 15 Learn & .024 & -.119 & .119 & .105 & .219 & .150 & -.070 & .230 & .172 & .070 & .660 & .594 & .552 & .411 & .649 & .514 & .522 & .543 & .503 & .506 & & & \\
\hline 15.1 Sense & .043 & -.088 & .114 & .054 & .175 & .107 & -.069 & .184 & .153 & .086 & .641 & .605 & .576 & .462 & .591 & .660 & .517 & .532 & .480 & .659 & .891 & & \\
\hline 15.2 Response & .097 & -.097 & .123 & .115 & .239 & .157 & -.036 & .235 & .185 & .054 & .683 & .569 & .581 & .453 & .658 & .458 & .515 & .532 & .501 & .514 & .918 & .795 & \\
\hline
\end{tabular}

Note: Absolute correlation values that are equal or higher than $0.123,0.157$, and 0.219 are significant at 0.10 . 0.05 and 0.01 levels respectively (two-tailed test); Item " 1 " to "10" are controls; Item " 11.1 " to " 11.3 " refer to three indicators of LIE; " 12.1 " = Consultancy support; " 12.2 " = Network support; “12.3” = Facility support. 
Table 6. Results for the structural model analysis.

\begin{tabular}{|c|c|c|c|c|c|c|c|c|}
\hline Item & Model 0 & Model 1 & Model 2 & Model 3 & Model 4 & Model 5 & Model 6 & Model 7 \\
\hline Metacog $\rightarrow$ LIE (H1) & $\begin{array}{l}0.259 \\
(2.932) \\
{[0.012 .0 .328]}\end{array}$ & $\begin{array}{l}0.258 \\
(2.930) \\
{[0.012 .0 .338]}\end{array}$ & $\begin{array}{l}0.256 \\
(2.832) \\
{[0.017 .0 .347]}\end{array}$ & $\begin{array}{l}0.258 \\
(2.930) \\
{[0.037 .0 .385]}\end{array}$ & $\begin{array}{l}0.255 \\
(2.790) \\
{[0.019 .0 .428]}\end{array}$ & $\begin{array}{l}0.254 \\
(2.770) \\
{[0.020 .0 .548]}\end{array}$ & $\begin{array}{l}0.255 \\
(2.790) \\
{[0.019 .0 .568]}\end{array}$ & $\begin{array}{l}0.252 \\
(2.732) \\
{[0.011 .0 .628]}\end{array}$ \\
\hline Network $\rightarrow$ LIE (H2) & $\begin{array}{l}0.418 *(4.969) \\
{[0.126 .0 .599]}\end{array}$ & $\begin{array}{l}0.416 *(4.930) \\
{[0.159 .0 .651]}\end{array}$ & $\begin{array}{l}0.408 *(4.786) \\
{[0.203 .0 .618]}\end{array}$ & $\begin{array}{l}0.417 *(4.944) \\
{[0.126 .0 .599]}\end{array}$ & $\begin{array}{l}0.399 *(4.581) \\
{[0.144 .0 .516]}\end{array}$ & $\begin{array}{l}0.389 *(3.569) \\
{[0.116 .0 .589]}\end{array}$ & $\begin{array}{l}0.346 *(3.426) \\
{[0.126 .0 .599]}\end{array}$ & $\begin{array}{l}0.336 *(3.069) \\
{[0.120 .0 .566]}\end{array}$ \\
\hline Learn $\rightarrow$ LIE (H3) & $\begin{array}{l}0.361(3.558) \\
{[0.076 .0 .561]}\end{array}$ & $\begin{array}{l}0.350(3.537) \\
{[0.103 .0 .557]}\end{array}$ & $\begin{array}{l}0.343(3.539) \\
{[0.145 .0533]}\end{array}$ & $\begin{array}{l}0.353(3.548) \\
{[0.105 .0 .566]}\end{array}$ & $\begin{array}{l}0.340(3.540) \\
{[0.075 .0 .561]}\end{array}$ & $\begin{array}{l}0.351(3.538) \\
{[0105.0 .567]}\end{array}$ & $\begin{array}{l}0.333(3.388) \\
{[0.066 .0 .560]}\end{array}$ & $\begin{array}{l}0.331(3.380) \\
{[0.060 .0 .559]}\end{array}$ \\
\hline Support1 $\rightarrow$ LIE & & $\begin{array}{l}0.078 \\
(0.957) \\
{[-0.041 .0 .224]}\end{array}$ & $\begin{array}{l}0.073 \\
(0.858) \\
{[-0.082 .0 .221]}\end{array}$ & & & & & $\begin{array}{l}0.060 \\
(2.588) \\
{[-0.077 .0 .321]}\end{array}$ \\
\hline $\begin{array}{l}\text { Support1 x Metacog } \\
\rightarrow \text { LIE (H3a) }\end{array}$ & & & $\begin{array}{l}0.049 \\
(-0.495) \\
{[-0.154 .0 .049]}\end{array}$ & & & & & $\begin{array}{l}0.044 \\
(-0.488) \\
{[-0.137 \cdot 0.149]}\end{array}$ \\
\hline Support2 $\rightarrow$ LIE & & & & $\begin{array}{l}0.189 * \\
(1.989) \\
{[0.026 .0 .570]}\end{array}$ & $\begin{array}{l}0.187 * \\
(1.988) \\
{[0.025 .0550]}\end{array}$ & & & $\begin{array}{l}0.188 * \\
(1.987) \\
{[0.036 .0 .561]}\end{array}$ \\
\hline $\begin{array}{l}\text { Support2 } \times \text { Network } \\
\rightarrow \text { LIE (H3b) }\end{array}$ & & & & & $\begin{array}{l}0.289(2.610) \\
{[0.070 .0560]}\end{array}$ & & & $\begin{array}{l}0.283(2.588) \\
{[0.076 .0 .561]}\end{array}$ \\
\hline Support3 $\rightarrow$ LIE & & & & & & $\begin{array}{l}0.168 * \\
(3.118) \\
{[0.016 .0 .461]}\end{array}$ & $\begin{array}{l}0.167 * \\
(3.018) \\
{[0.017 .0 .561]}\end{array}$ & $\begin{array}{l}0.163^{*} \\
(2.988) \\
{[0.014 .0 .778]}\end{array}$ \\
\hline $\begin{array}{l}\text { Support3 } \times \text { Learn } \rightarrow \\
\text { LIE (H3c) }\end{array}$ & & & & & & & $\begin{array}{l}0.228^{*} \\
(2.600) \\
{[0.176 .0 .664]}\end{array}$ & $\begin{array}{l}0.225^{*} \\
(2.588) \\
{[0.170 .0 .756]}\end{array}$ \\
\hline Hub $\rightarrow$ LIE (CV) & $\begin{array}{l}-0.157 \\
(-2.560)\end{array}$ & $\begin{array}{l}-0.156 \\
(-2.574)\end{array}$ & $\begin{array}{l}-0.145 \\
(-2.760)\end{array}$ & $\begin{array}{l}-0.152 \\
(-2.584)\end{array}$ & $\begin{array}{l}-0.146 \\
(-2.574)\end{array}$ & $\begin{array}{l}-0.147 \\
(-2.560)\end{array}$ & $\begin{array}{l}-0.147 \\
(-2.560)\end{array}$ & $\begin{array}{l}-0.159 \\
(-2.612)\end{array}$ \\
\hline Age $\rightarrow$ LIE (CV) & $\begin{array}{l}0.129 * \\
(2.999)\end{array}$ & $\begin{array}{l}0.133 * \\
(3.678)\end{array}$ & $\begin{array}{l}0.132 * \\
(3.670)\end{array}$ & $\begin{array}{l}0.130 * \\
(3.098)\end{array}$ & $\begin{array}{l}0.125^{*} \\
(2.789)\end{array}$ & $\begin{array}{l}0.129 * \\
(2.999)\end{array}$ & $\begin{array}{l}0.129 * \\
(2.999)\end{array}$ & $\begin{array}{l}0.121^{*} \\
(2.110)\end{array}$ \\
\hline Size $\rightarrow$ LIE (CV) & $\begin{array}{l}-0.016 \\
(-0.250)\end{array}$ & $\begin{array}{l}-0.025 \\
(-0.299)\end{array}$ & $\begin{array}{l}-0.022 \\
(-0.239)\end{array}$ & $\begin{array}{l}-0.025 \\
(-0.299)\end{array}$ & $\begin{array}{l}-0.016 \\
(-0.250)\end{array}$ & $\begin{array}{l}-0.016 \\
(-0.250)\end{array}$ & $\begin{array}{l}-0.015 \\
(-0.244)\end{array}$ & $\begin{array}{l}-0.011 \\
(-0.181)\end{array}$ \\
\hline Layer $\rightarrow$ LIE (CV) & $\begin{array}{l}-0.003 \\
(-0.034)\end{array}$ & $\begin{array}{l}-0.009 \\
(-0.094)\end{array}$ & $\begin{array}{l}-0.008 \\
(-0.088)\end{array}$ & $\begin{array}{l}-0.008 \\
(-0.088)\end{array}$ & $\begin{array}{l}-0.007 \\
(-0.693)\end{array}$ & $\begin{array}{l}-0.008 \\
(-0.084)\end{array}$ & $\begin{array}{l}-0.005 \\
(-0.034)\end{array}$ & $\begin{array}{l}-0.003 \\
(-0.034)\end{array}$ \\
\hline $\begin{array}{l}\text { Department } \rightarrow \text { LIE } \\
(\mathrm{CV})\end{array}$ & $\begin{array}{l}0.005 \\
(0.075)\end{array}$ & $\begin{array}{l}-0.004 \\
(0.068)\end{array}$ & $\begin{array}{l}0.005 \\
(0.075)\end{array}$ & $\begin{array}{l}0.006 \\
(0.078)\end{array}$ & $\begin{array}{l}0.005 \\
(0.075)\end{array}$ & $\begin{array}{l}0.004 \\
(0.068)\end{array}$ & $\begin{array}{l}0.004 \\
(0.068)\end{array}$ & $\begin{array}{l}0.005 \\
(0.075)\end{array}$ \\
\hline $\begin{array}{l}\text { TMT Number } \rightarrow \text { LIE } \\
(\mathrm{CV})\end{array}$ & $\begin{array}{l}0.063 \\
(0.077)\end{array}$ & $\begin{array}{l}0.060 \\
(0.066)\end{array}$ & $\begin{array}{l}0.057 \\
(0.056)\end{array}$ & $\begin{array}{l}0.061 \\
(0.067)\end{array}$ & $\begin{array}{l}0.060 \\
(0.066)\end{array}$ & $\begin{array}{l}0.061 \\
(0.067)\end{array}$ & $\begin{array}{l}0.057 \\
(0.056)\end{array}$ & $\begin{array}{l}0.053 \\
(0.047)\end{array}$ \\
\hline $\begin{array}{l}\text { TMT Industry } \rightarrow \text { LIE } \\
(\mathrm{CV})\end{array}$ & $\begin{array}{l}0.088^{*} \\
(1.992)\end{array}$ & $\begin{array}{l}0.084 \dagger \\
(1.920)\end{array}$ & $\begin{array}{l}0.084 \dagger \\
(1.920)\end{array}$ & $\begin{array}{l}0.088 \dagger \\
(1.949)\end{array}$ & $\begin{array}{l}0.073 \dagger \\
(1.822)\end{array}$ & $\begin{array}{l}0.088 \dagger \\
(1.949)\end{array}$ & $\begin{array}{l}0.088^{*} \\
(1.992)\end{array}$ & $\begin{array}{l}0.076 \dagger \\
(1.769)\end{array}$ \\
\hline $\begin{array}{l}\text { TMT Education } \rightarrow \\
\text { LIE (CV) }\end{array}$ & $\begin{array}{l}-0.080 \dagger \\
(-1.535)\end{array}$ & $\begin{array}{l}-0.080 \dagger \\
(-1.535)\end{array}$ & $\begin{array}{l}-0.088^{*} \\
(-1.992)\end{array}$ & $\begin{array}{l}-0.085 \dagger \\
(-1.386)\end{array}$ & $\begin{array}{l}-0.080 \dagger \\
(-1.535)\end{array}$ & $\begin{array}{l}-0.088^{*} \\
(-1.992)\end{array}$ & $\begin{array}{l}-0.080 \dagger \\
(-1.535)\end{array}$ & $\begin{array}{l}-0.073 \\
(-1.236)\end{array}$ \\
\hline $\begin{array}{l}\text { TMT Risk } \rightarrow \text { LIE } \\
(\mathrm{CV})\end{array}$ & $\begin{array}{l}-0.047 \\
(-0.801)\end{array}$ & $\begin{array}{l}-0.049 \\
(-0.819)\end{array}$ & $\begin{array}{l}-0.049 \\
(-0.867)\end{array}$ & $\begin{array}{l}-0.040 \\
(-0.664)\end{array}$ & $\begin{array}{l}-0.041 \\
(-0.654)\end{array}$ & $\begin{array}{l}-0.049 \\
(-0.819)\end{array}$ & $\begin{array}{l}-0.047 \\
(-0.801)\end{array}$ & $\begin{array}{l}-0.038 \\
(-0.574)\end{array}$ \\
\hline $\begin{array}{l}\text { Innovativeness } \rightarrow \text { LIE } \\
(\mathrm{CV}) \\
\text { Endogenous variable }\end{array}$ & $\begin{array}{l}-0.015 \\
(-0.265)\end{array}$ & $\begin{array}{l}-0.020 \\
(-0.354)\end{array}$ & $\begin{array}{l}-0.023 \\
(-0.425)\end{array}$ & $\begin{array}{l}-0.024 \\
(-0.517)\end{array}$ & $\begin{array}{l}-0.012 \\
(-0.222)\end{array}$ & $\begin{array}{l}-0.020 \\
(-0.354)\end{array}$ & $\begin{array}{l}-0.015 \\
(-0.265)\end{array}$ & $\begin{array}{l}-0.022 \\
(-0.426)\end{array}$ \\
\hline LIE $\left[\mathrm{R}^{2}\right.$. Adjusted $\left.\mathrm{R}^{2}\right]$ & [0.792. 0.764] & [0.794. 0.764] & {$[0.795 .0 .763]$} & [0.792. 0.764] & [0.803. 0.772] & [0.795. 0.764] & [0.805. 0.764] & [0.812. 0.772] \\
\hline $\begin{array}{l}\text { Cohen's } f^{2} \\
\text { Metacog } \rightarrow \text { LIE (H1) }\end{array}$ & & & & & & & & \\
\hline Metacog $\rightarrow$ LIE (H1) & 0.246 & 0.245 & 0.238 & 0.247 & 0.245 & 0.248 & 0.246 & 0.243 \\
\hline Network $\rightarrow$ LIE (H2) & 0.260 & 0.259 & 0.256 & 0.259 & 0.257 & 0.258 & 0.257 & 0.255 \\
\hline Learn $\rightarrow$ LIE (H3) & 0.251 & 0.244 & 0.252 & 0.247 & 0.246 & 0.251 & 0.249 & 0.248 \\
\hline $\begin{array}{l}\text { Support1 x Metacog } \\
\rightarrow \text { LIE (H3a) }\end{array}$ & & & 0.010 & & & & & 0.009 \\
\hline $\begin{array}{l}\text { Support2 x Network } \\
\rightarrow \text { LIE (H3b) }\end{array}$ & & & & & 0.233 & & & 0.232 \\
\hline $\begin{array}{l}\text { Support3 } \times \text { Learn } \rightarrow \\
\text { LIE }(\text { H3c) }\end{array}$ & & & & & & & 0.228 & 0.226 \\
\hline
\end{tabular}

Note: $t$-values in parentheses; Bootstrapping 95\% confidence interval bias corrected in square bracket (based on $n=5000$ subsamples); $\dagger p<0.10 .{ }^{*} p<0.05 . p<0.01$. ${ }^{*} p<0.001$ [based on $n=5000$, two-tailed test]; $C V=$ control variable. 